بررسى تأثير جهت و موقعيت شيب بر برخى شاخصهاى ميكروبى خاى در زمين هاى مر تعى و جنگلى

على اشرف سلطانى طولارود": دانشيار كروه علوم و مهندسى خاك، دانشكدمى كشاورزى و منابع طبيعى، دانشكاه محقق اردبيلى، اردبيل

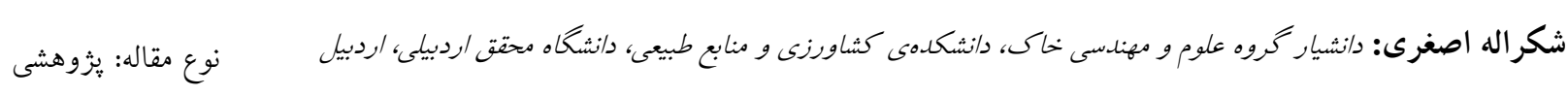

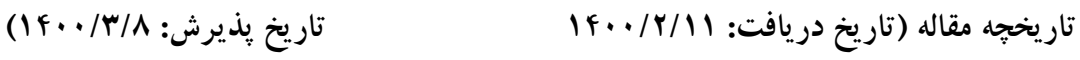

جكيده

مطالعلى شاخصهاى كيفيت خاك در كاربرىهاى متفاوت و بر روى بخشهاى مختلف زمينهاى شيبدار

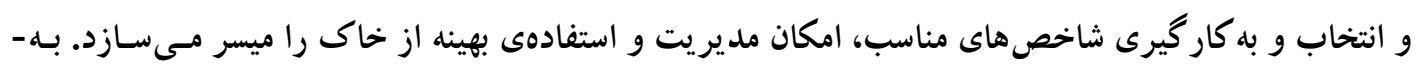

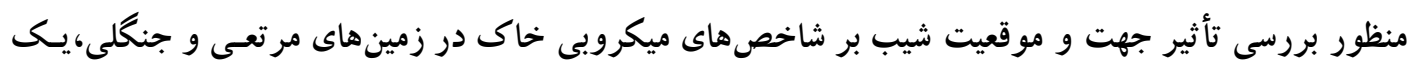

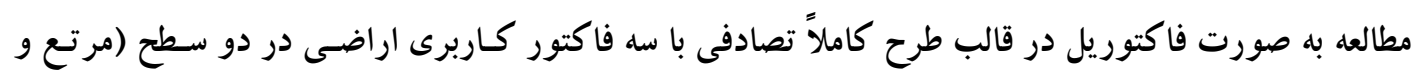

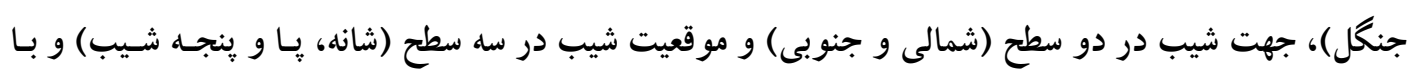

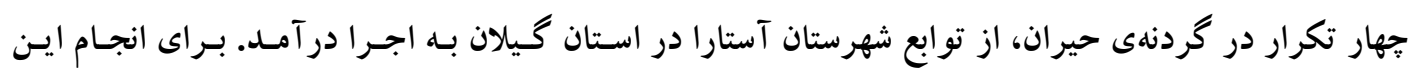

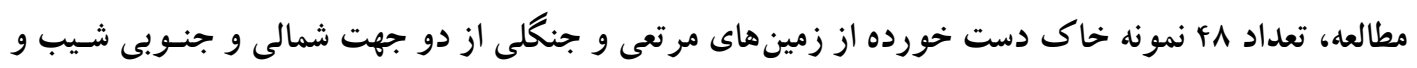

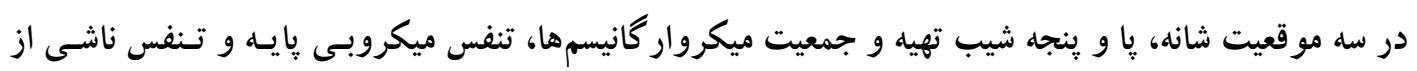

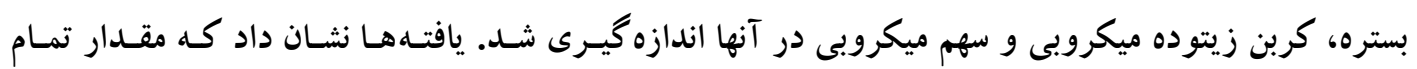

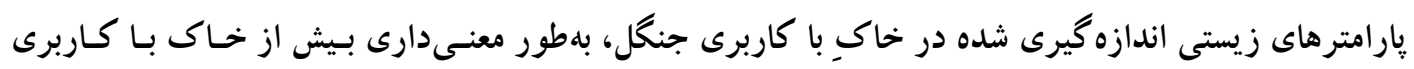

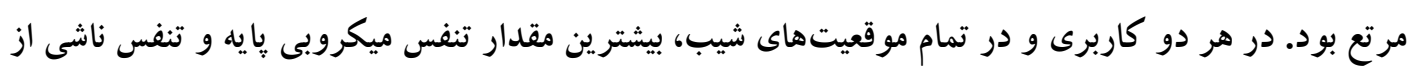

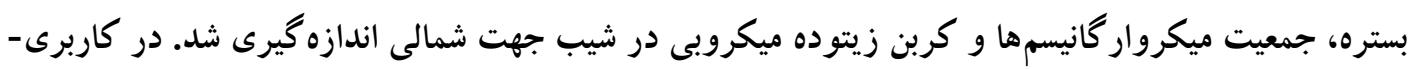

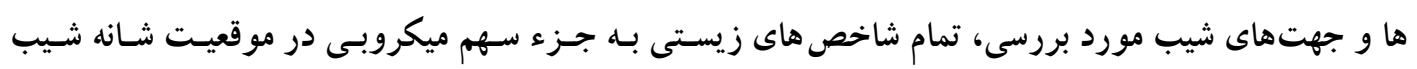
بالاترين مقدار را داشتند. بيشترين مقـدار سهم ميكروبسى (1/9هmgC شمالى بازمى گشت كه با مقدار اين شاخص در موقعيتهاى يا و ينجه شيب واقع در جهت شمالى، همجنين شانه

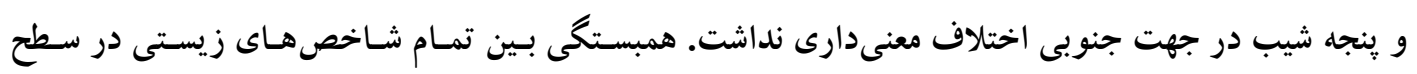

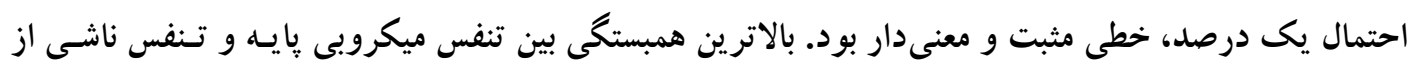

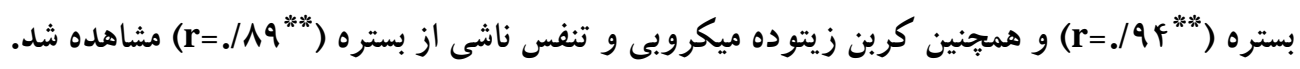

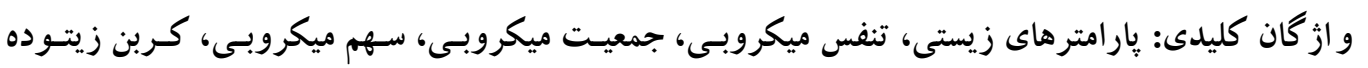
ميكروبى، كيفيت خاك، گردنهى حيران. 


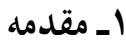

خاكى بهعنوان يكى از اجزاى مهم محيط زيست، در صورتى كه كيفيت آن حفظ شود و بهبود يابد، مىتوانسـ نقـش مهمى در اكوسيستمهاى طبيعى و دستساز بشر ايفا كند. كيفيت خاكى و توانايى و ظرفيت آن در انجام دادن وظـايف

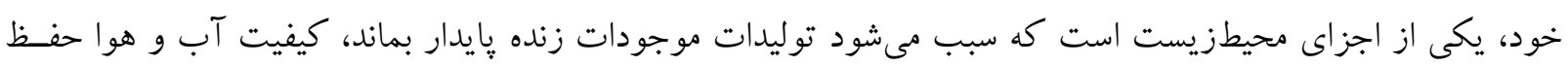

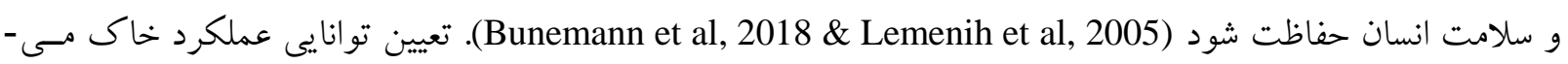

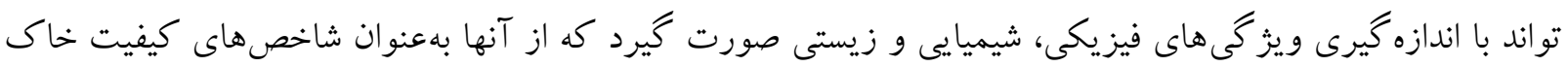

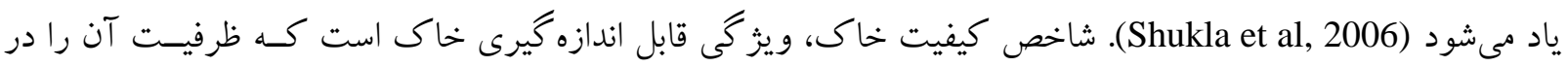
ايفاى يك نقش تعيينشده تحت تأثير قرار مىدهد. ويز گیىهايى از خاك كه به تغييرات ايجــاد شــه در آن، در نتيجـهـ

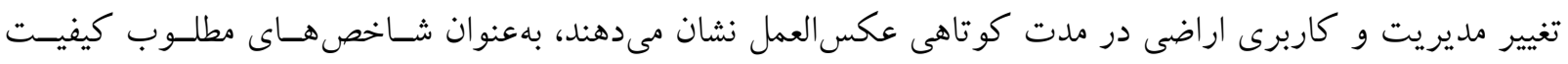

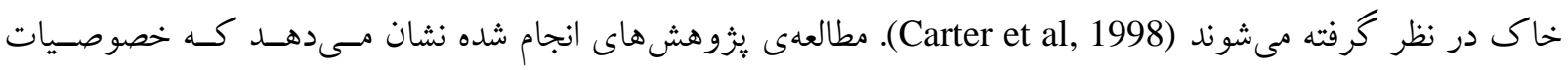

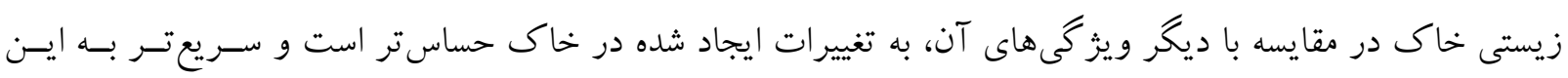

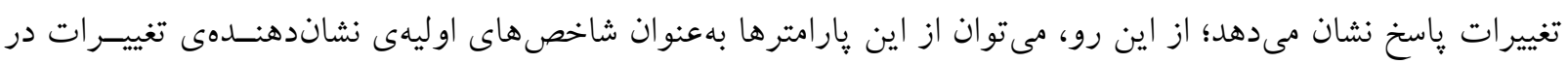

خاك، در ارزيابى كيفيت خاكى استفاده كرد (Geisseler and Horwath, 2009).

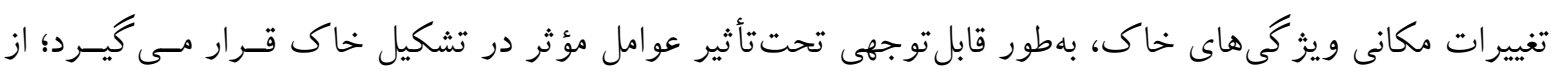

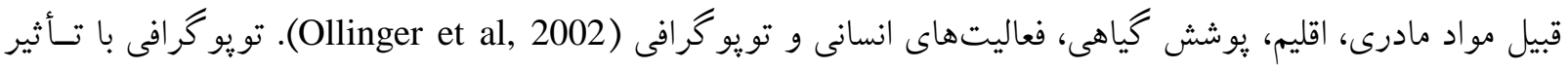

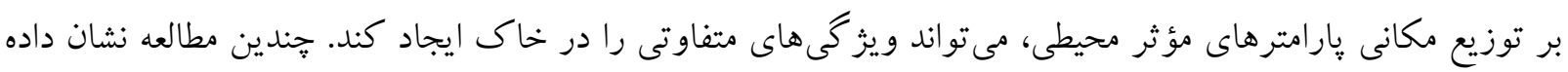
است كه موقعيت شيب بر ويز گیىاى خاك تأثير مى گذارد (Alemayehu, 2007 \& Yimer et al, 2008). اين متغيـر تويوگرافى با تأثير بر ميزان نفوذ آب در خاك، حركت و تجمع محلول خاكى و رسوب مواد و دما، به ايجاد تغييـرات

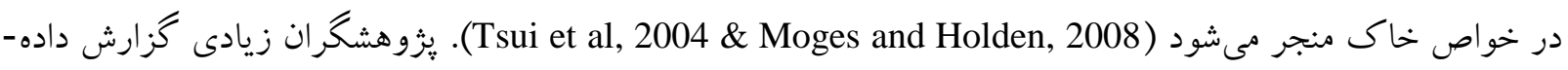
اند كه تغيير در مقدار كربن آلى، رطوبت، pH، نيتروزن كل، حاصلخيزى و شاخص هاى ميكروبى خاك، تحست تـأثير موقعيت شيب صورت مى گيرد (Smith et al, 2002 \& Khormali et al, 2009 \& Reza et al, 2011). جهت شيب بهـ

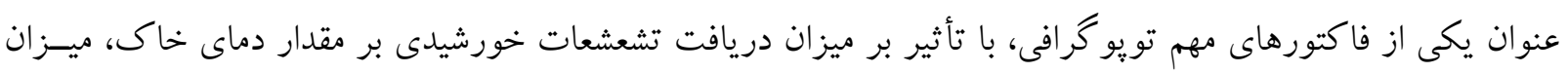

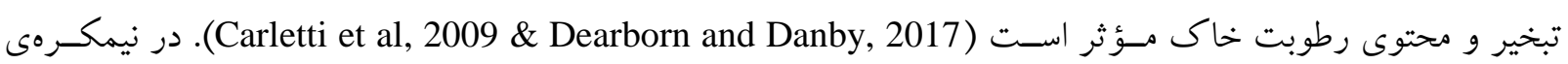

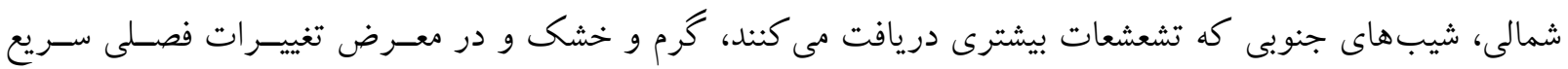
هستند و بالعكس، شيبهاى شمالى تشعشعات كمترى دريافت مى كنند و خنكى و مرطوب هستند و تغييرات فصسلى در آنها كم است (Sariyildiz et al, 2005). محققان مختلفى اثر جهت شيب را بر ويز كى هاى فيزيكى و شيميايى (از قبيل

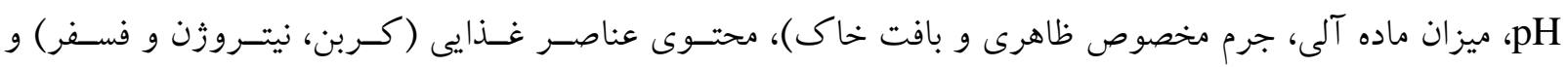

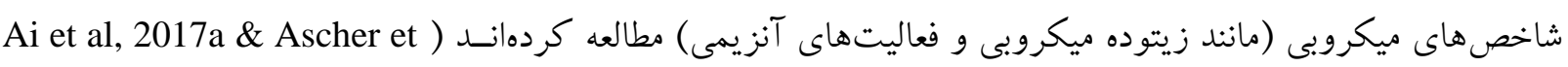
al, 2012 \& Gilliam et al, 2014 \& Huang et al, 2015 \& Sidari et al, 2008 \& Qin et al, 2016 \& Bardelli et .(al, 2017 \& Liu et al, 2017 مطالعهى يزوهشهاى محققان نشان مىدهد كه يكى ديخر از عوامل مؤثر بر ويز كىهاى خـاك، كـاربرى اراضسى

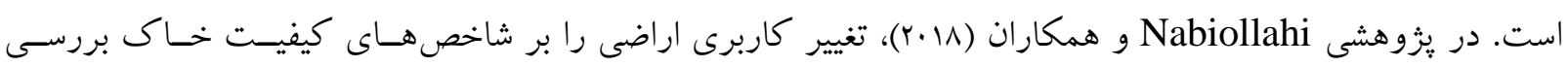


كردند. اين محققان كزارش كردند كه خواص خاك شامل pH، هدايت الكتريكى، كربن آلى، ظرفيت تبادل كاتيونى، مواد خنثىشونده، فرسايش يذيرى خاك، جرم مخصوص ظاهرى، تخلخل كل و ميانگين وزنى قطر خاكدانه ها در اراضى كرئ

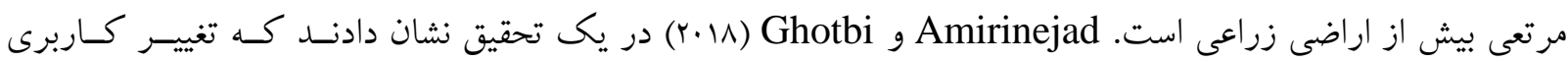

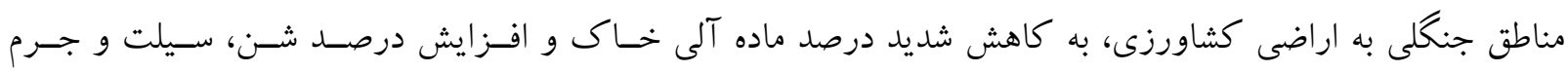

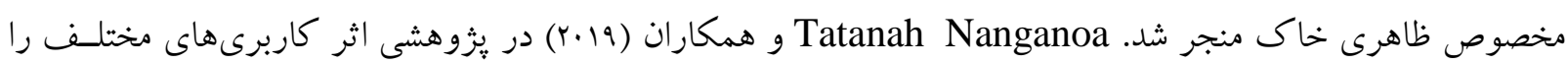

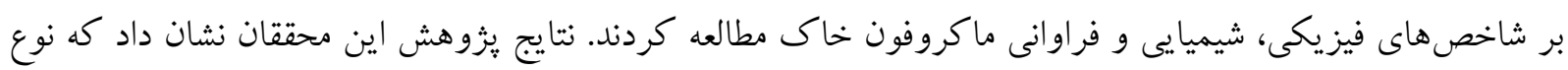

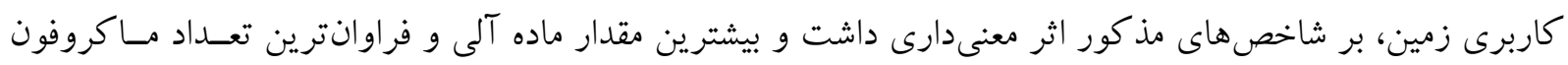

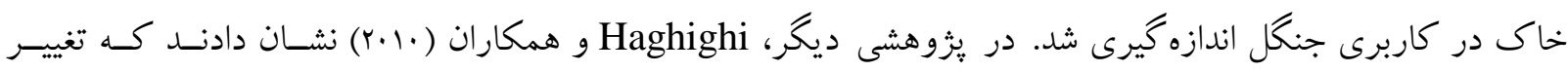

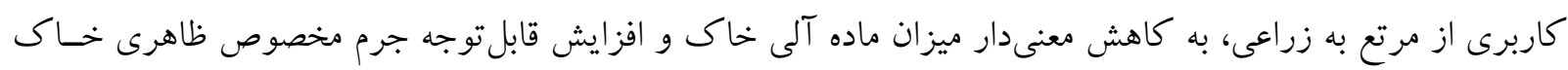

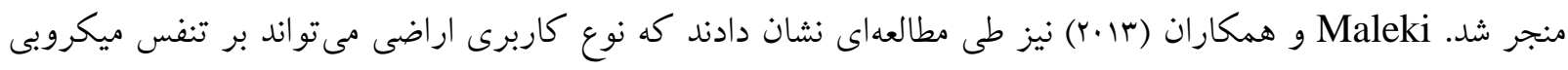

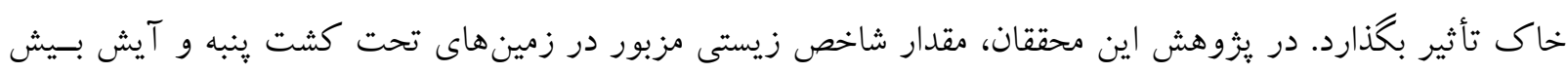
از زمينهاى شخمخورده بود.

كردنهى حيران، منطقهاى است در روستاى حيران از توابع شهرستان آستارا كه در مسير راه ارتباطى آستارا ــ اردبيل

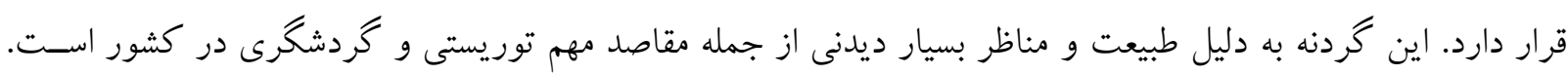

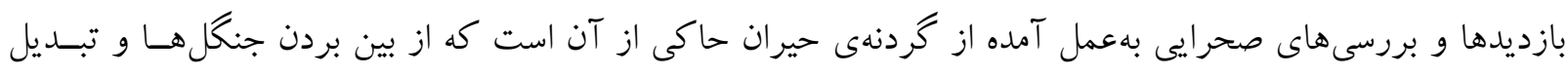

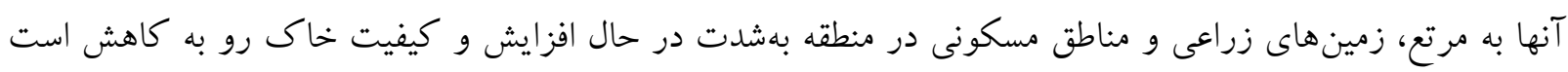

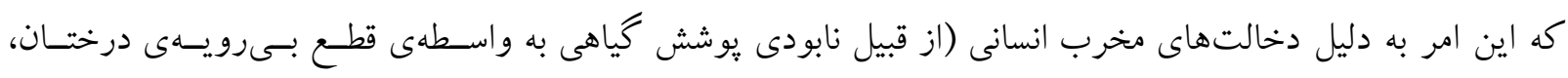

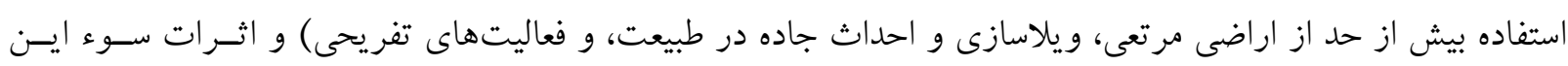

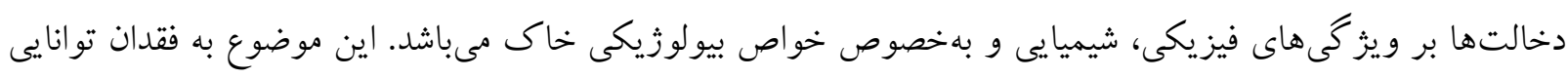

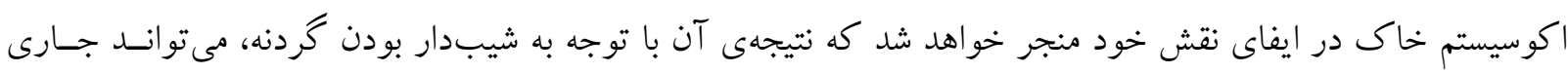

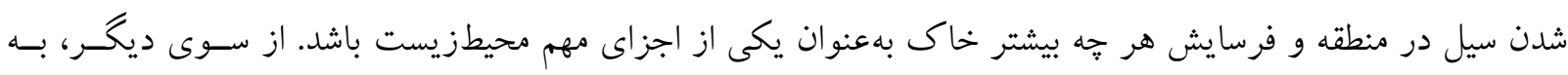

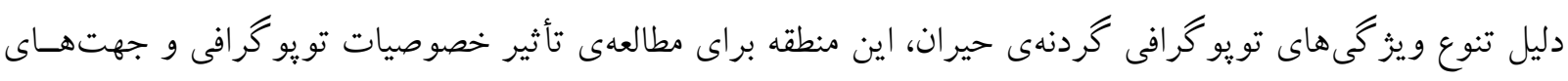

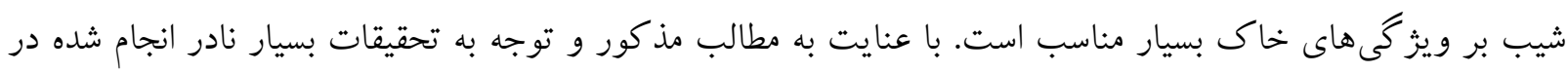

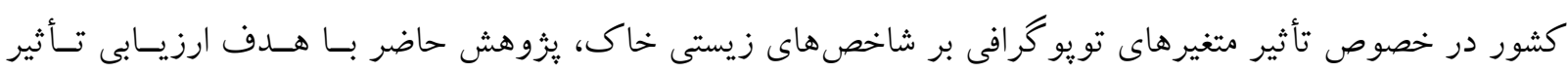
جهت و موقعيت شيب بر برخى از شاخصهاى ميكروبى خاك در زمينهاى مرتعى و جنكلى اين كردنه انجام شد.

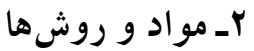

\section{منطقهى مورد مطالعه و تهيهى نمونههاى خاك}

منطقهى مورد مطالعه، اراضى واقع در گردنهى حيران از توابع شهرستان آستارا در استان گيلان است. اين منطقـه در

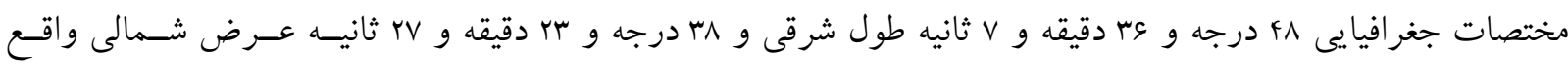


براى اجراى اين يزوهش، ^^ نمونه خاك دستخورده از عمق · تا • ا سانتىمترى زمين هاى مرتعى و جنكلسى از دو

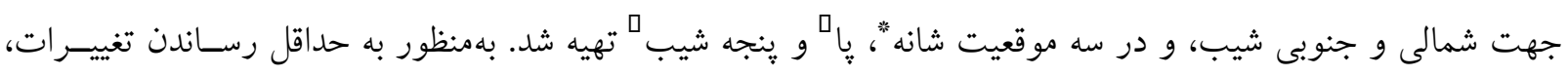

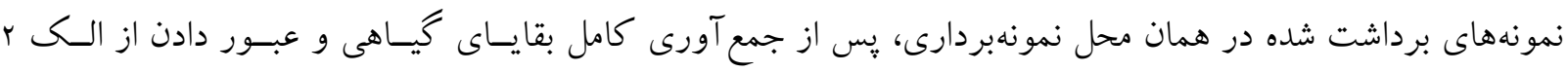

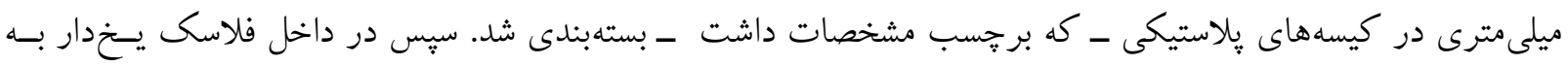

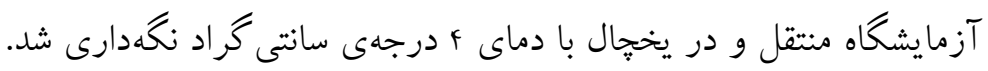

\section{اندازه گيرى شاخصهاى زيستى}

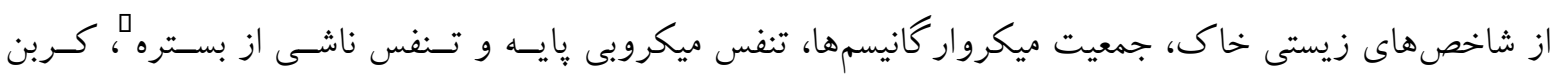

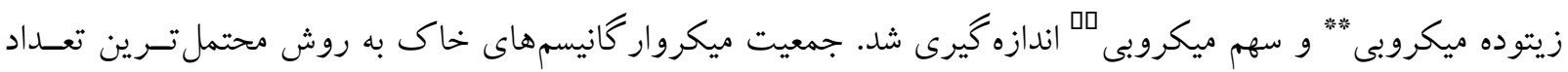

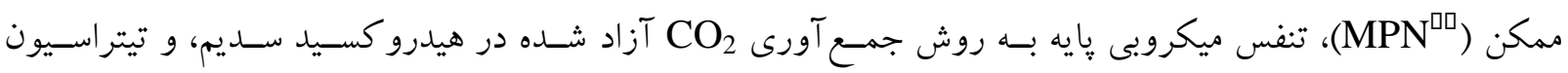

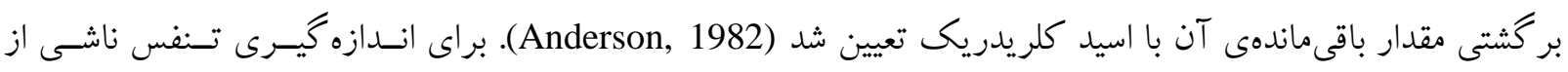

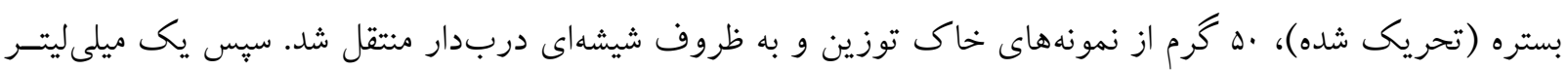

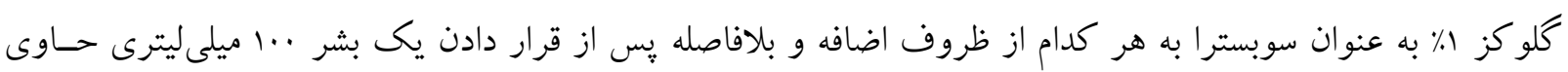

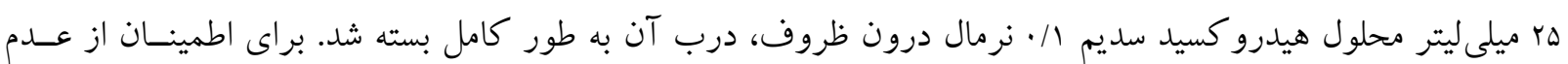

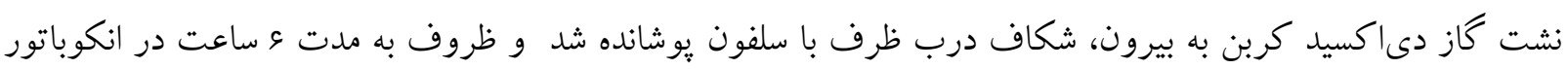

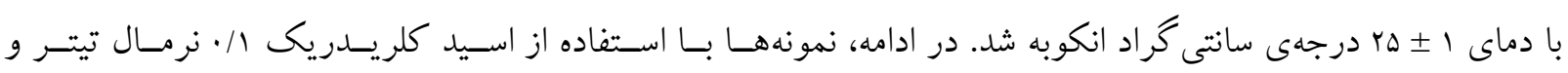
مقدار CO آزاد شده محاسبه و در نهايت، ميزان تنفس ناشى از بستره تعيين شد (Alef and Nannipieri, 1995). كربن

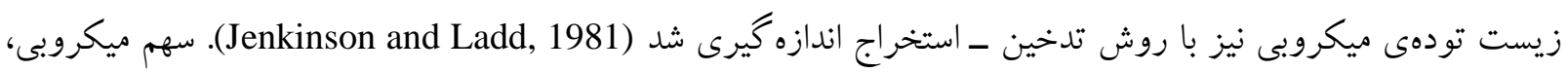

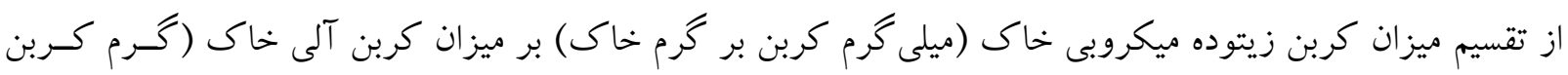
بر كرم خاك) به دست آمد (Martens, 1991).

\section{طرح آزمايشى و تجزيه و تحليل آمارى دادههاى يزوهش}

اين آزمايش به صورت فاكتوريل در قالب طرح كاملاً تصادفى انجام شد. فاكتورهاى آزمايش شامل كاربرى اراضى در دو سطح (مرتع و جنگل)، جهت شيب در دو سطح (شمالى و جنوبى) و موقعيت شيب در سه سطح (شانه، يا و ينجه

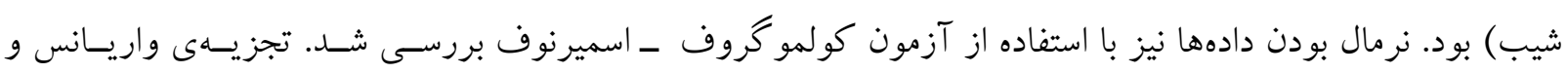

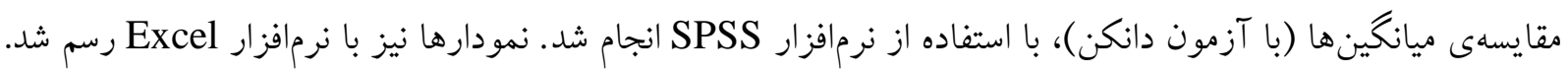

\footnotetext{
* shoulder

$\dagger$ footslope

* toeslope

$\S$ Substrate Induced Respirations; SIR

** Microbial Biomass Carbon; MBC

† Microbial quotient

\#ost Probable Number
} 
آمارههاى توصيفى برخى از خواص فيزيكى و شيميايى اندازه گيرى شده در خاك جنحـل و مرتـع، بـهـترتيـب در

جدولهاى او ب آورده شدهاست (Asghari and Shahab, 2020).

جدول ا: آمارههاى توصيفى :بارامترهاى اندازه گيرى شده در خاى جنگل

\begin{tabular}{|c|c|c|c|c|c|c|}
\hline متغير & واحد & حداقل & حداكثر & ميانكين & انحراف استاندارد & ضريب تغييرات \\
\hline $\mathrm{B}_{\mathrm{d}}$ & $\left(\mathrm{g} / \mathrm{cm}^{3}\right)$ & $1 / 1$. & $1 / 0$ & $1 / \% \Lambda$ &.$/ 111$ & $9 / r 1$ \\
\hline
\end{tabular}

$\begin{array}{llllll}D_{\mathrm{p}} & \left(\mathrm{g} / \mathrm{cm}^{3}\right) \quad \mathrm{r} / \mathrm{Tr} & \mathrm{r} / \Delta \mathrm{VV} & \mathrm{r} / \mathrm{TV} & . / 1 \Delta & \mathrm{g} / \mathrm{Tr}\end{array}$

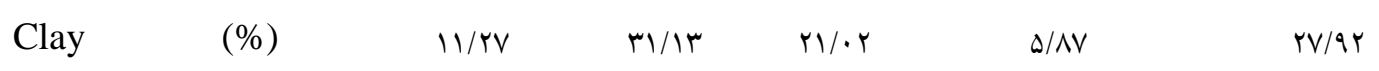

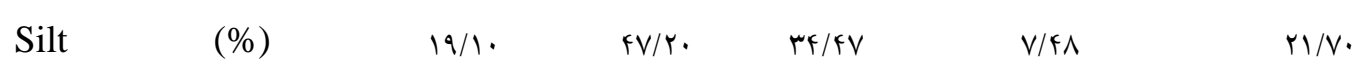

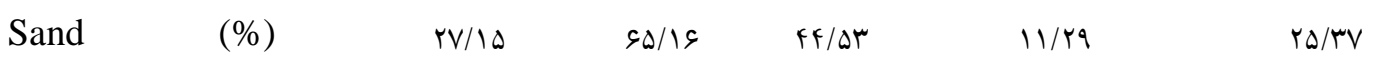

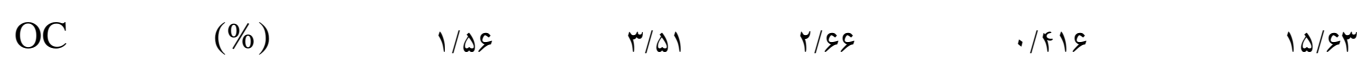

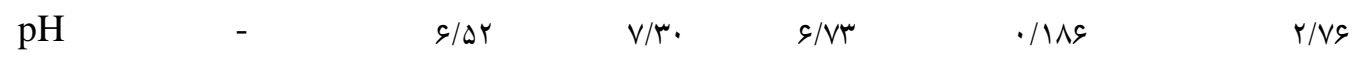

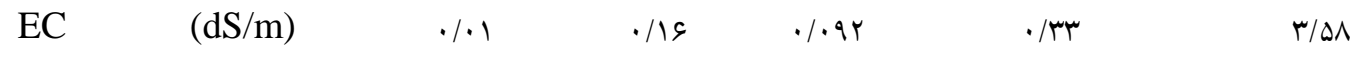

$\begin{array}{lllllll}\mathrm{CaCO}_{3} & (\%) & \& & 1 \cdot / \Lambda \cdot & N / \Delta r & 1 / \Delta V & \mathrm{~N}\end{array}$

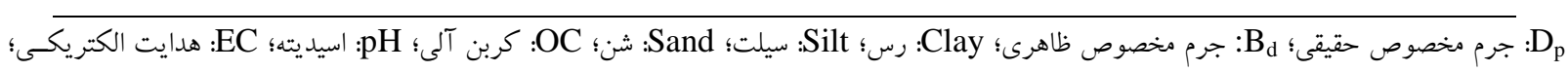

\begin{tabular}{|c|c|c|c|c|c|c|}
\hline متغير & واحد & حداقل & حداكثر & ميانگين & انحراف استاندارد & ضريب تغييرات \\
\hline $\mathrm{Bd}$ & $\left(\mathrm{g} / \mathrm{cm}^{3}\right)$ & $1 / T \Delta$ & | آهك./1 & $1 / \% \Lambda$ & $\cdot / \cdot 11$ & $\Delta / \Lambda \varepsilon$ \\
\hline $\mathrm{D}_{\mathrm{p}}$ & $\left(\mathrm{g} / \mathrm{cm}^{3}\right)$ & $r / T r$ & $r / \Delta \Lambda$ & $r / r \Lambda$ &.$/ 18$ & $s / V Y$ \\
\hline Clay & $(\%)$ & $r \cdot / M$ & $F N / 8 \mid$ & $M / / \&$ S & $s / v$ & $r y / r q$ \\
\hline Silt & $(\%)$ & $r \mid / r q$ & DI/.r & $r \Delta / \Delta F$ & $s / \Delta$ & $\mid N / T \Lambda$ \\
\hline Sand & $(\%)$ & $19 / 11$ & $\mathrm{Fq/ve}$ & rY/QV & N/rs & $r \Delta / T_{\Delta}$ \\
\hline $\mathrm{OC}$ & $(\%)$ & $1 / 48$ & $r / A r$ & $r / \Gamma 1$ & 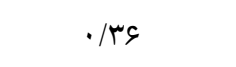 & $\mid Q / g r$ \\
\hline $\mathrm{pH}$ & - & S/Qr & s/Aq & s/sq &.$/ 11$ & r/VG \\
\hline $\mathrm{EC}$ & $(\mathrm{dS} / \mathrm{m})$ & $\cdot / r$ & . & $\cdot / \cdot 19$ & $\cdot / \cdot r \mid$ & $r \Psi / \Delta q$ \\
\hline $\mathrm{CaCo}_{3}$ & $(\%)$ & 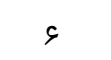 & $1 \cdot / \wedge$ & $N / \Delta r$ & $1 / \Delta V$ & IN/FY \\
\hline
\end{tabular}


جدول ץ: تجزيهى روايانس اثر كاربرى اراضى، جهت و موقعيت شيب بر شاخصهاى ميكروبى خاك

\begin{tabular}{|c|c|c|c|c|c|c|}
\hline \multicolumn{5}{|c|}{ ميانگين مربعات } & \multirow{3}{*}{ آزادى درجه } & \multirow{3}{*}{ منابع تغييرات } \\
\hline 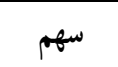 & كربن زيتوده & جمعيت & ت تنفس ناشى از & تنفس ميكروبى & & \\
\hline ميكروبى & ميكروبى & ميكروبى & بستره & 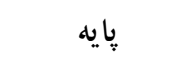 & & \\
\hline$r / r S^{*}$ & rוrqهq" & VYrT. . ** & $s|s| f^{* * *}$ & $\cdot / \% q V^{* * *}$ & 1 & كاربرى زمين \\
\hline$\cdot / \mu I V^{*}$ & $q \uparrow \mu r \varphi^{* * *}$ & rq५ & $\mu / \cdot \Delta Q^{* * *}$ & $\cdot / 191^{* * *}$ & 1 & جهت شيب \\
\hline$\cdot / r 90^{*}$ & 19499*** & $1 \cdot v^{2} v^{* * a s}$ & $\cdot / \mu \cdot V^{* * *}$ & $\cdot / \cdot 11^{* * *}$ & r & موقعيت شيب \\
\hline$\cdot / \mu \mid f^{*}$ & $9 V \mid f^{* * *}$ & $r \wedge V^{* * *}$ & $\cdot / \cdot \wedge \varepsilon^{* * *}$ & $\cdot / \cdot 1 r^{* * *}$ & 1 & كاربرى × جهت \\
\hline$\cdot / .9 s^{\mathrm{ns}}$ & MVIS & $1 . \Delta S V^{* * *}$ & $\cdot / \cdot \uparrow \Lambda^{* * *}$ & $\cdot / \cdot \Delta^{* * *}$ & r & كاربرى × موقعيت \\
\hline . /YSE* & $M r^{n s}$ & $V \cdot r q^{* * *}$ & $\cdot / \cdot r f^{\mathrm{ns}}$ & $\cdot / \cdot \mid r^{* * *}$ & r & جهت × موقعيت \\
\hline$\cdot / \cdot \Delta \Lambda^{\mathrm{ns}}$ & $r \cdot r^{\mathrm{ns}}$ & $s \wedge q r^{* * *}$ & $\cdot / \cdot 1 r^{\mathrm{ns}}$ & $\cdot / \cdot 4^{* * * *}$ & r & كاربرى × جهت × مو قعيت \\
\hline- & - & - & - & - & re & 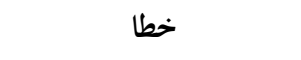 \\
\hline s/r.r & $r / \Delta$. & $r \cdot / \Lambda$ & $1 . / \mathrm{VA}$ &.$/ 894$ & - & ضريب تغييرات \\
\hline
\end{tabular}

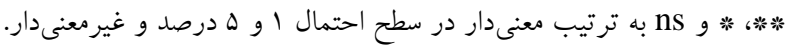

با توجه به دادههاى تجزيهى واريانس، اثر اصلى كاربرى، جهت و موقعيت شيب بر سهم ميكروبى در سطح احتمـال

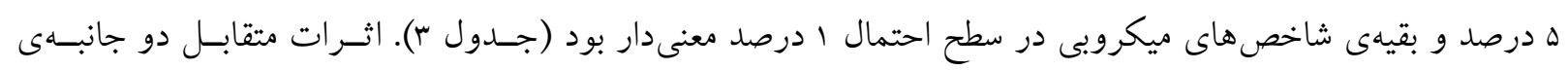

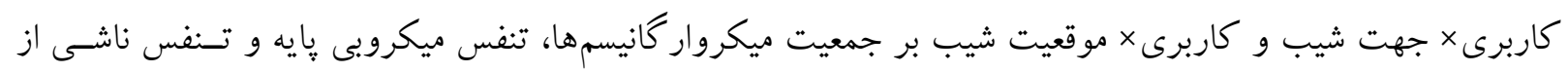
بستره و كربن زيتوده ميكروبى، تفاوت معنىدارى در سطح احتمال ا درصد داشت. در خصـوص ســــم ميكروبسى نيـز اثرات دو جانبهى كاربرى × جهت شيب و جهت شيب× موقعيت شيب، در سطح احتمال ه درصد معنىدار بود. در ايسن

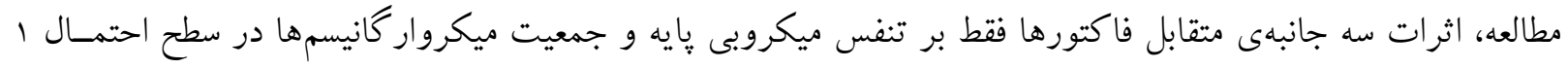
درصد معنى دار بود (جدول r).

\section{جمعيت ميكروار كانيسمهاى خاك}

يافته هاى اين تحقيق نشان داد كه اثر اصلى فاكتورهاى مورد مطالعه و اثرات متقابـل دو و سـه جانبـهى آنهـا، بــر

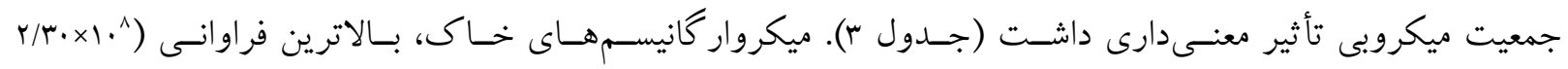
ميكروار كانيسم در هر گرم خاك خشك) را در موقعيت شانه شيب و در جهت شمالى كاربرى جنكل داشت. كمترين

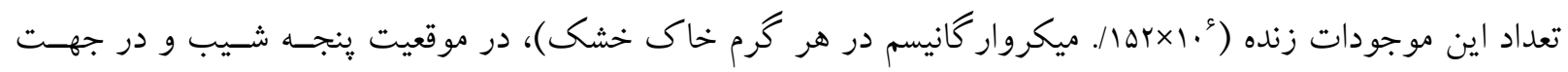
جنوبى كاربرى مرتع مشاهده شد كه با ساير موقعيتهاى شيب در دو جهت شمالى و جنوبى كاربرى مزبسـور اخستلاف

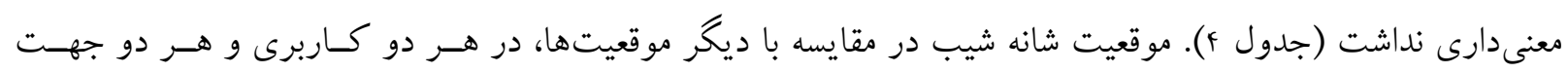

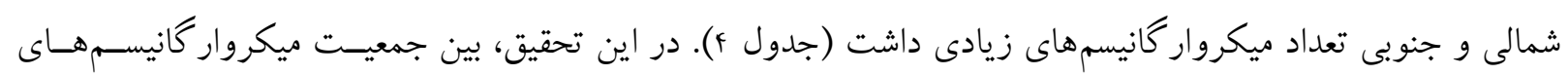

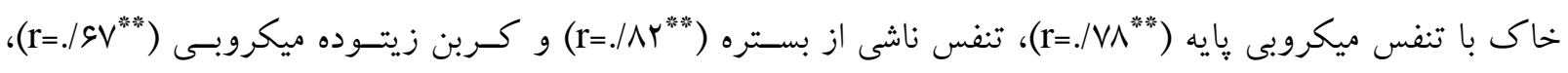

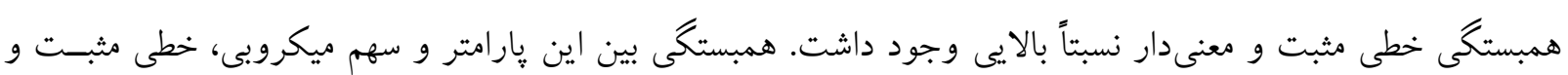

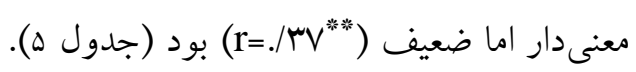


جدول f: مقايسهى ميانكين اثر كاربرى اراضى، جهت و موقعيت شيب بر تنفس ميكروبى بايه و جمعيت ميكروار گانيسمهاى خاك

\begin{tabular}{|c|c|c|c|c|}
\hline 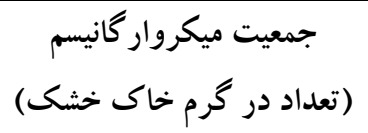 & $\begin{array}{c}\mathrm{mgCO}_{2} \text { · g-1. تنفس ميكروبى پايه } \\
\left(\text { day }^{-1}\right)\end{array}$ & موقعيت شيب & جهت شيب & كاربرى اراضى \\
\hline$r / r \cdot \times 1 \cdot^{\wedge a}$ & $\cdot /\left\{\lambda \cdot c^{a}\right.$ & شانه شيب & & \multirow{6}{*}{ جنكل } \\
\hline $1 / 1 \cdot \times 1 \cdot{ }^{\wedge b}$ & $\cdot / k r k^{b}$ & ياى شيب & شمالى & \\
\hline$. / 49 \times 1 \cdot{ }^{\wedge c}$ & $\cdot / 4 / f^{b}$ & ينجه شيب & & \\
\hline$. / F|\times| \cdot .^{\text {ccd }}$ & $\cdot|r \Delta|^{c}$ & شانه شيب & \multirow{3}{*}{ جنوبى } & \\
\hline$\cdot / r \Delta \times \mid \cdot{ }^{\text {Ade }}$ & $\cdot / \mu \cdot r^{d}$ & ياى شيب & & \\
\hline$\cdot / 19 \times 1 \cdot{ }^{\text {Aef }}$ &.$/ 190$ ef & ينجه شيب & & \\
\hline $1 / K f \times 1.9 f$ & $\cdot / r q^{\mathrm{e}}$ & شانه شيب & \multirow{3}{*}{ شمالى } & \multirow{6}{*}{ مرتع } \\
\hline$\cdot / \Delta r \times 1.9 f$ & $\cdot / r \mid r^{\mathrm{ef}}$ & ياى شيب & & \\
\hline$\cdot / \mu \mid \times 1.9 f$ & $\cdot / r \mu \cdot{ }^{e}$ & ينجه شيب & & \\
\hline$\cdot / r \Lambda \times 1 .^{.9 f}$ & $\cdot /|V|^{f}$ & شانه شيب & & \\
\hline$. /|9| \times \mid \cdot{ }^{.9 f}$ & $\cdot / 1 r^{g}$ & ياى شيب & جنوبى & \\
\hline.$/|\Delta r \times| \cdot{ }^{s f}$ & $\cdot / \cdot 9 v^{g}$ & ينجه شيب & & \\
\hline
\end{tabular}

در هر ستون، ميانكينهاى با حروف غيرمشابه داراى اختلاف معنىدارى در سطح احتمال ا درصد هستند.

\section{تنفس ميكروبى خاك}

در ئزوهش حاضر، اثر اصلى و اثرات متقابل دو و سه جانبهى فاكتورهاى مورد مطالعه بر تنفس ميكروبى پايـه، در

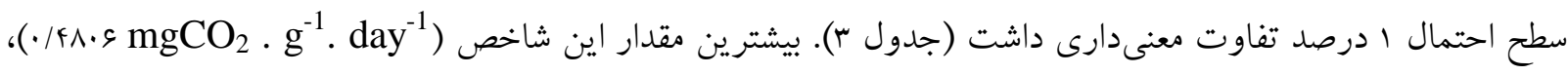

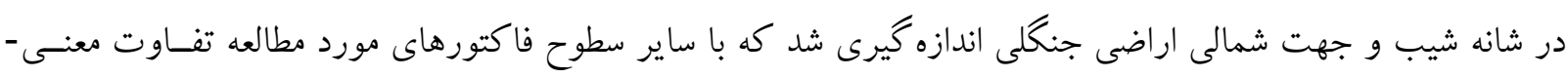
دارى داشت. تنفس ميكروبى پايه، كمترين مقدار (

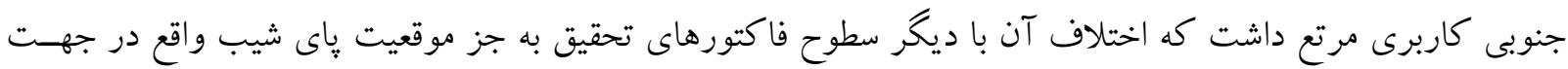
جنوبى كاربرى مذكور معنى دار بود (جدول \&). نتايج حاصل از تجزيهى واريانس دادهها نيز نشان داد كه اثرات متقابـل

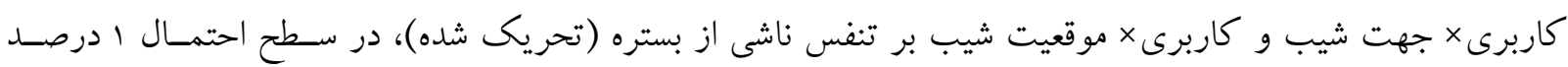

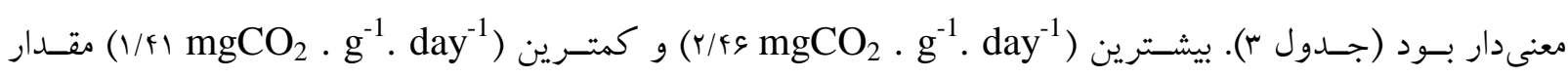
شاخص مزبور نيز به ترتيب در شانه شيب خاك جنكل و ينجه شيب خاك مرتع مشاهده شد (شكل الف الف). با توجه به شكل ا (ب)، تنفس ناشى از بستره در خاك جنكل واقع در شيب شمالى، بيشترين (r/aV mgCO

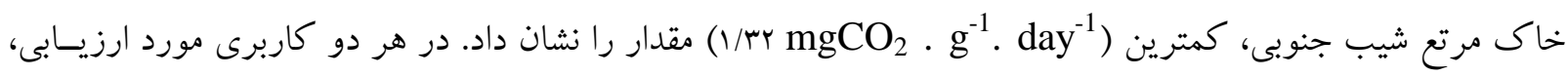
مقدار تنفس ميكروبى (يايه و تنفس ناشى از بستره) در شيب جنوبى كمتر از شيب شمالى بود (جدول أ و شكل اب).

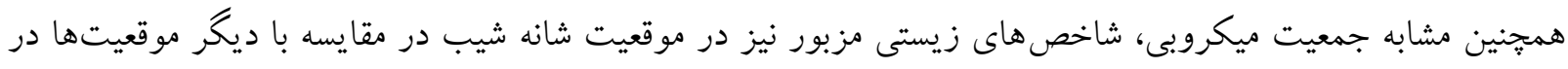

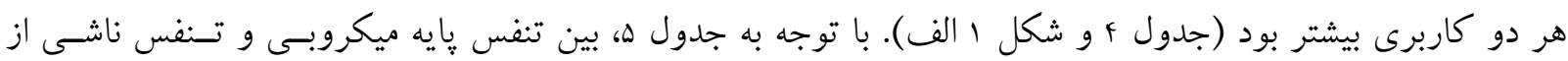

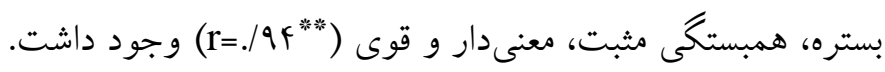



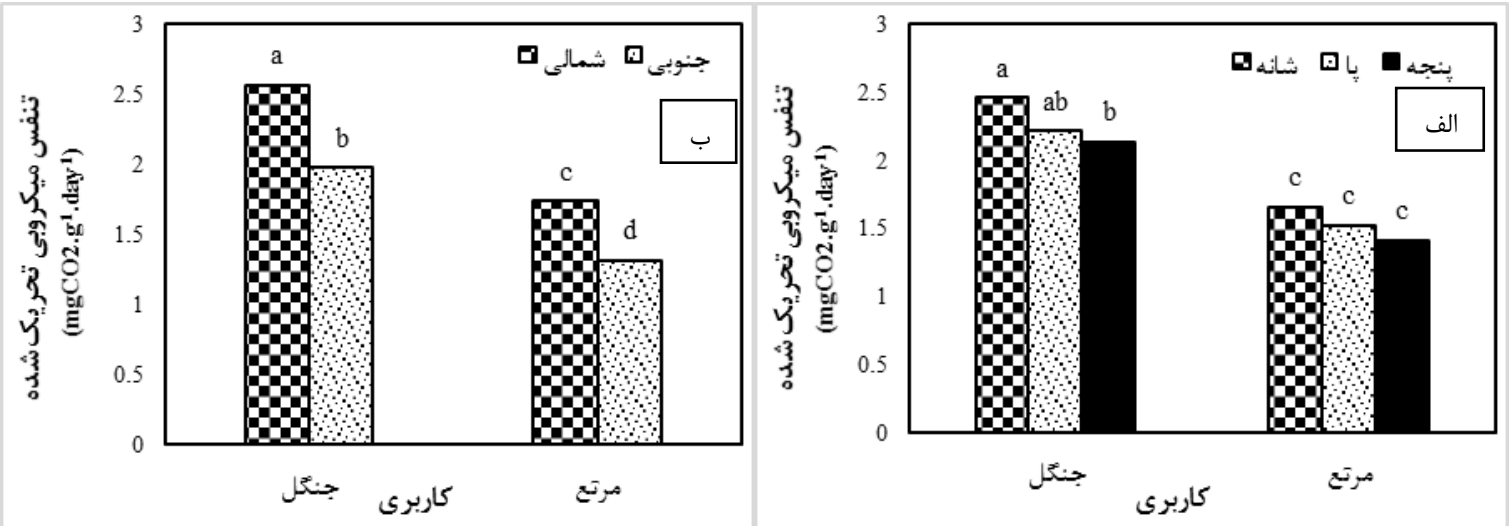

شكل ا: اثرات متقابل كاربرى × موقعيت شيب (الف) و كاربرى × جهت شيب (ب) بر تنفس ناشى از بستره (تحريك شده)

حروف غيرمشابه، بيانغر اختلاف معنىدار در سطح احتمال ا درصد است.

$$
\text { كربن زيتوده ميكروبى }
$$

نتايج تجزيه واريانس دادها نشان داد كه اثر اصلى كاربرى و متغيرهاى موقعيت و جهت شيب، همجنين اثر متقابل كاربرى × جهت شيب و كاربرى × موقعيت شيب بر كربن زيتوده ميكروبى معنى دار بود (جدول ب). مقايسهى ميـانكين دادهها نشان داد كه اين شاخص، بيشترين مقدار (SM mgC داد؛ هر تهند كه اختلاف معنىدارى با ساير موقعيت ها در اين كاربرى وجود نداشت. يايينترين مقــدار كـربن زيتـوده ميكروبى (ric. g موقعيت پإى شيب كاربرى مرتع) اختلاف معنىدارى داشت (شكل r الف). تغيير جهت شيب به تغييـر مقــدار كـربن

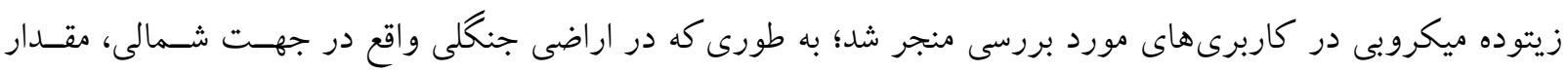
شاخص مزبور () و جنوبى اراضى مرتع بيشتر بود (شكل r ب). در ثيزوهش ييشرو، بين كربن زيتوده ميكروبى با تنفس ميكروبى بايسه

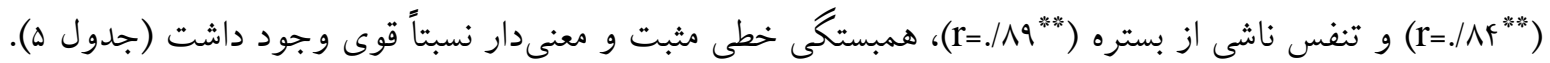
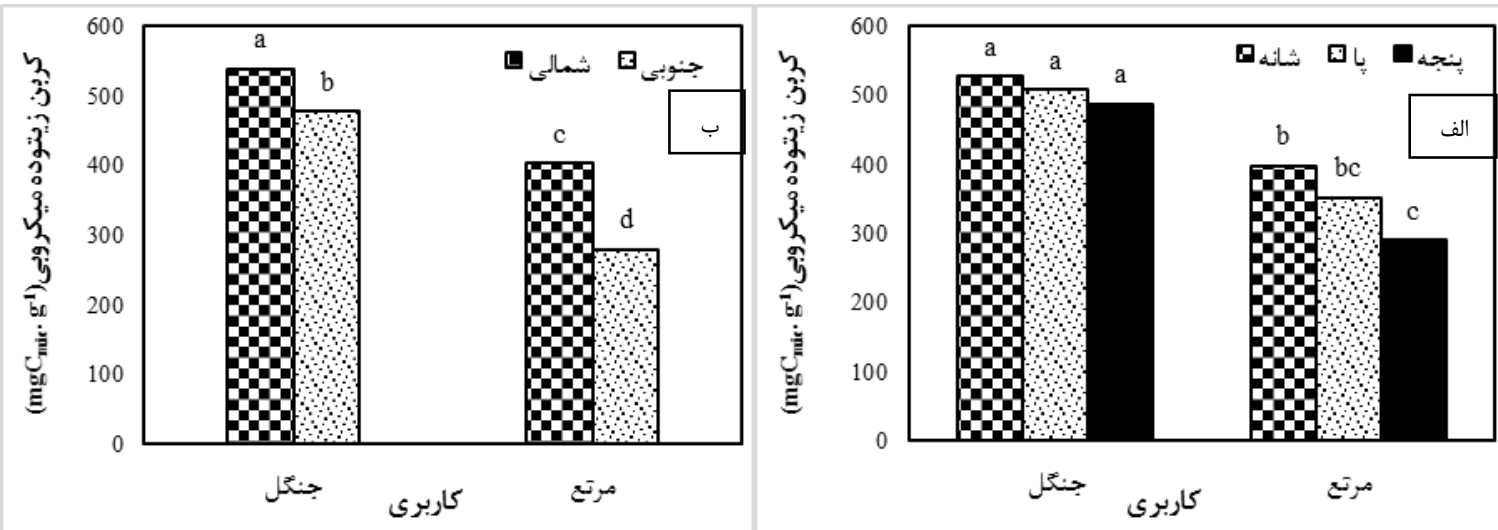

شكل ץ: اثرات متقابل كاربرى × موقعيت شيب (الف) و كاربرى × جهت شيب (ب) بر كربن زيتوده ميكروبى مكي 


\section{سهم ميكروبى}

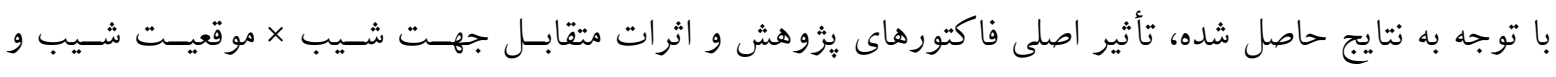

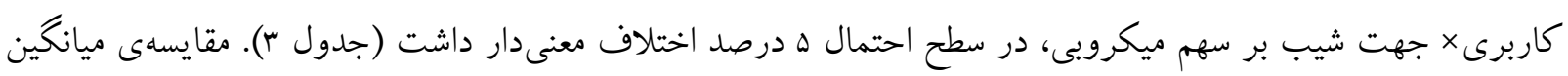
در شكل ץ (ب) نشان مىدهد كه بيشترين مقدار سهم ميكروبى، مربوط به شانه شيب در جهت شمالى است كه با مقدار

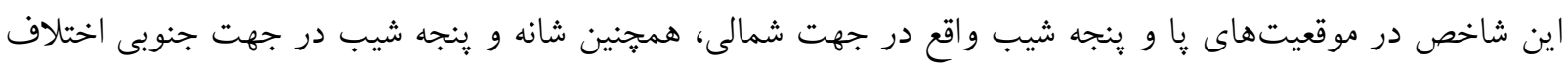
معنى دارى نداشت. مقدار سهم ميكروبى در دو جهت شـمالى (1/91 mgC mic.g (1/9 ${ }^{1} C_{\text {org }}$

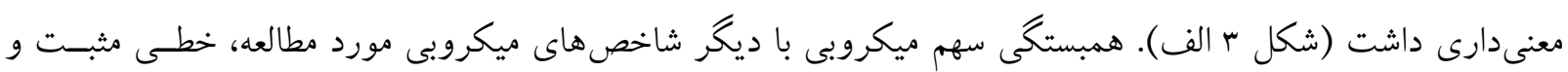

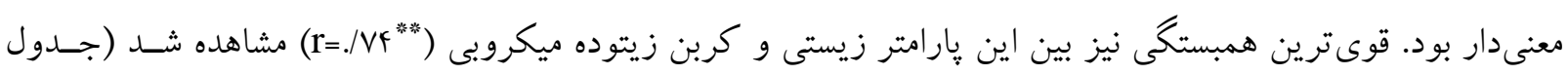
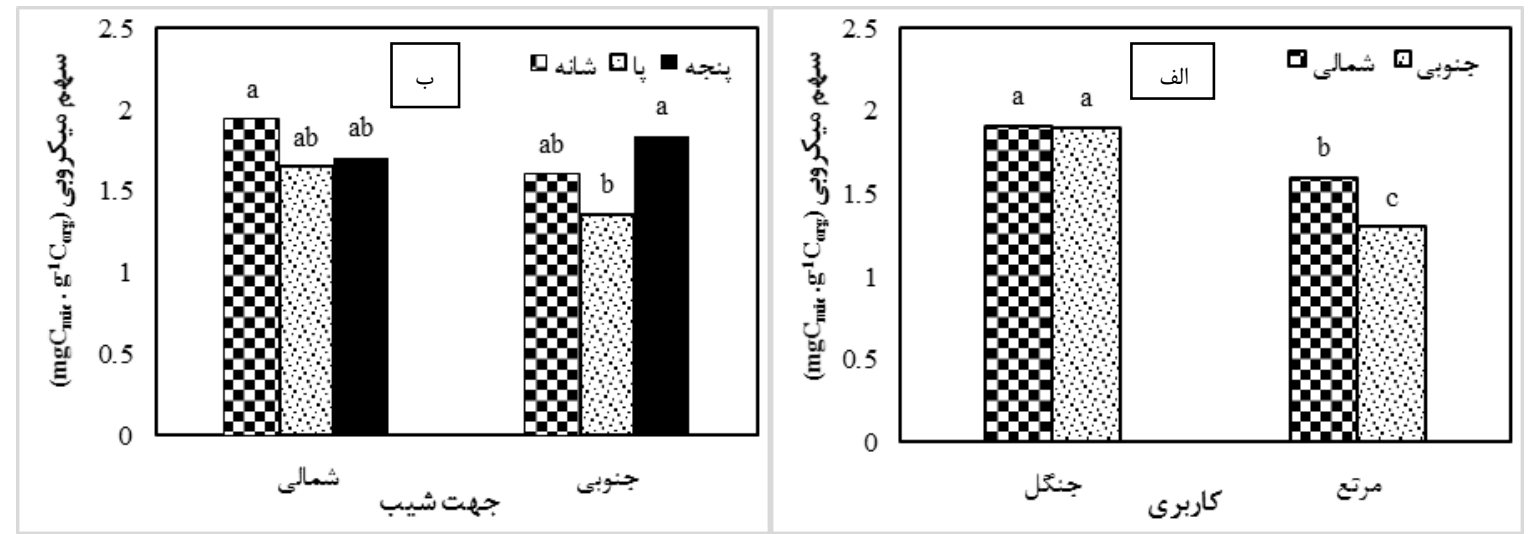

شكل ץ: اثرات متقابل كاربرى × جهت شيب (الف) و جهت شيب × موقعيت شيب (ب) بر سهم ميكروبى

حروف غيرمشابه بيانگر اختلاف معنىدار در سطح احتمال ه درصد است.

جدول ه: همبستخى هاى بيرسون بين شاخصهاى ميكروبى خاى

\begin{tabular}{|c|c|c|c|c|c|}
\hline $\mathbf{q}_{\text {mic }}$ & MBC & MPN & SIR & BR & شاخص هاى \\
\hline & & & & 1 & BR \\
\hline & & & 1 & $\cdot / 948^{* * * 2 *}$ & SIR \\
\hline & & 1 & $\cdot / \Lambda r^{* * * *}$ & $\cdot / \mathrm{V} \Lambda^{* * * *}$ & MPN \\
\hline & 1 & $\cdot / \& V^{* * * * 5}$ & $\cdot / 19^{* * * *}$ & $\cdot / \Lambda F Q^{* * * *}$ & MBC \\
\hline 1 & $\cdot / V F^{* * *}$ & $\cdot / \mu V^{* * *}$ & $\cdot / 09^{* * * *}$ & $\cdot / \mathbb{k} \mathbb{R}^{* * * * *}$ & $\mathbf{q}_{\text {mic }}$ \\
\hline
\end{tabular}

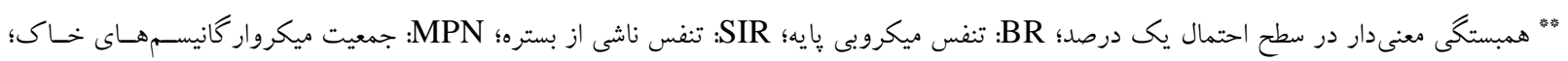

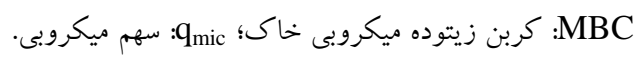


F

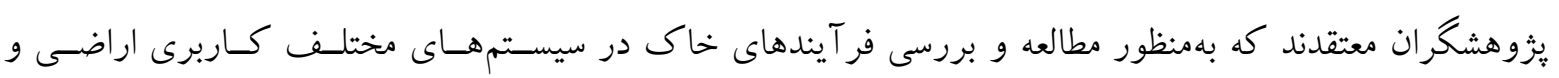

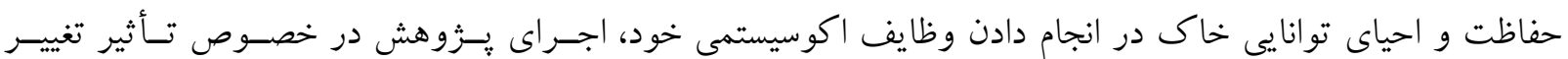

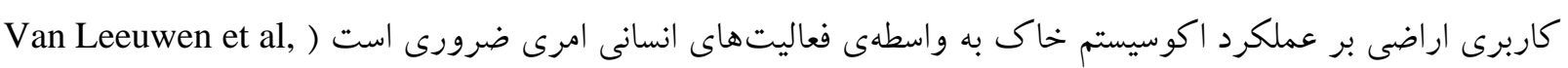

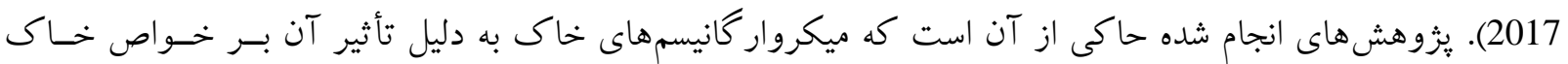

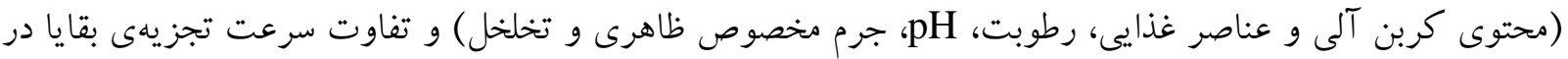

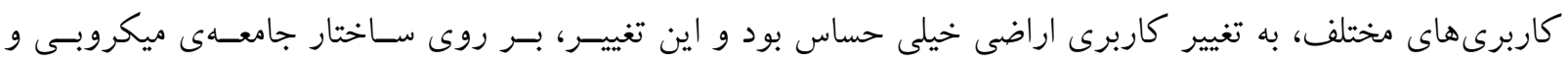

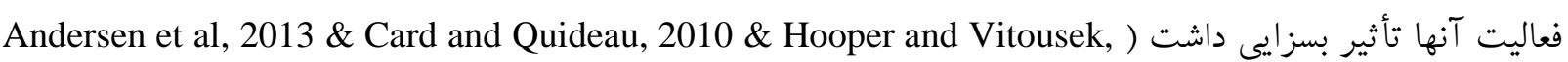
هodiab et al, 2020 \& Soui et al, 2019

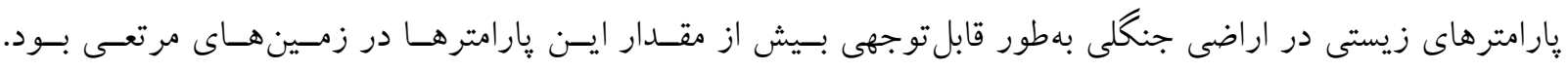

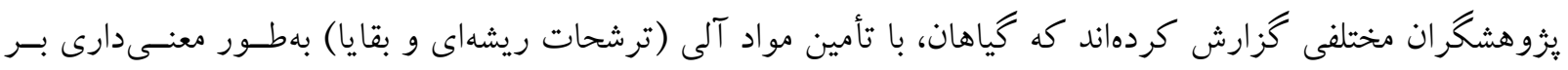

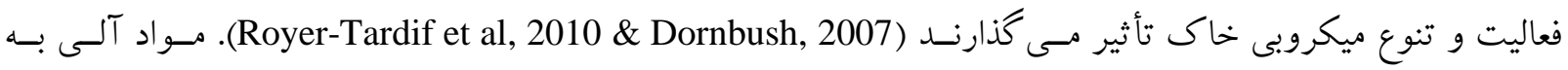

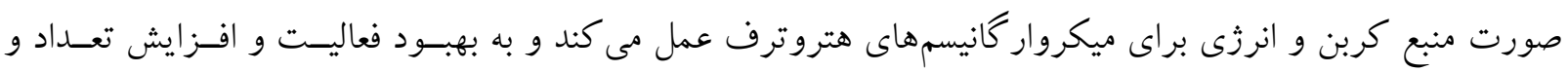

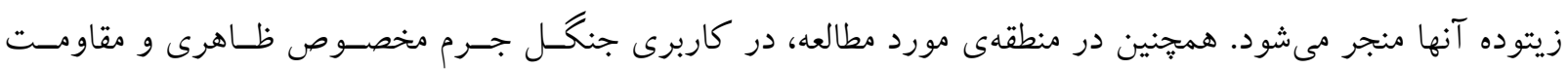

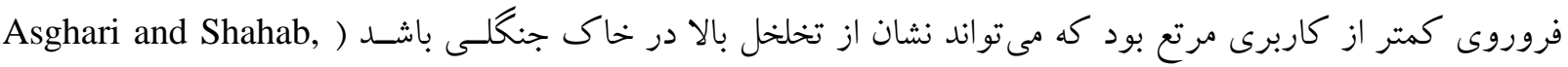

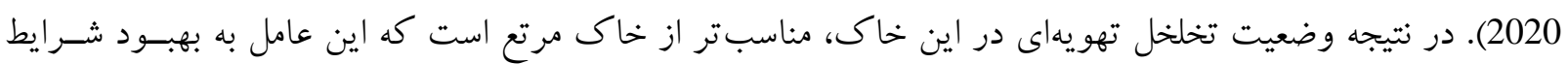

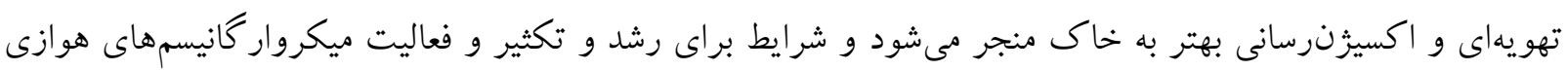

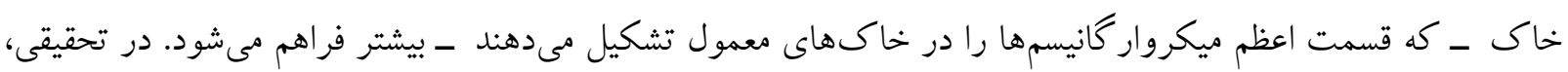

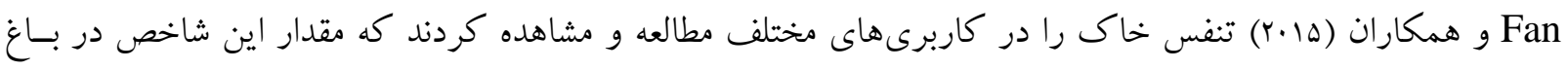

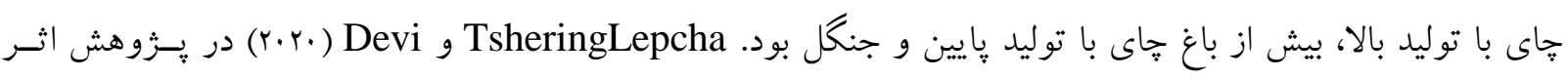

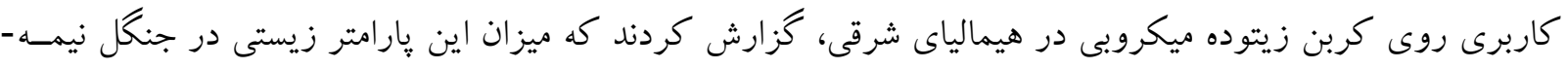

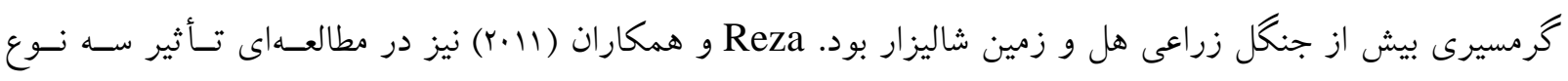

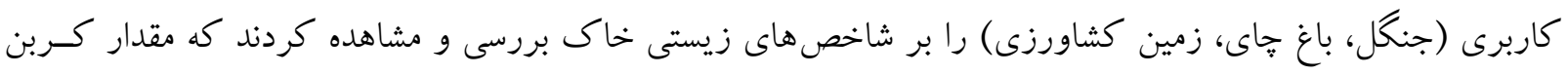

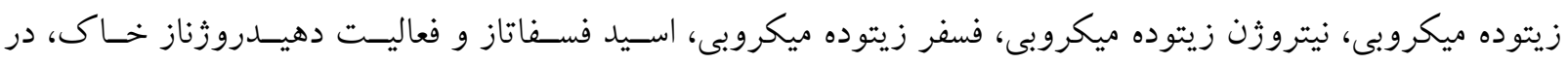

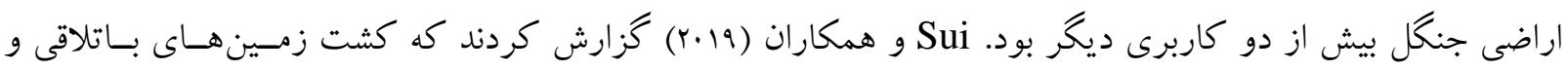
مرداب با تغيير مخازن كربن، نيتروزن و فسفر خاك؛ تنوع باكترىها، قارجها و ساختار جامعهى ميكروبى را به واسطه-

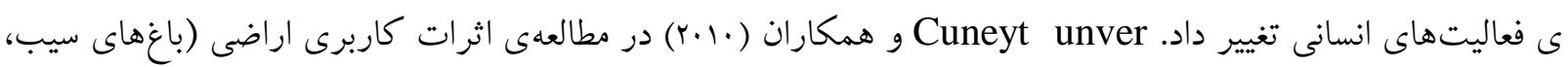

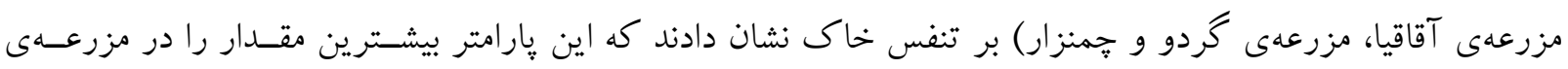

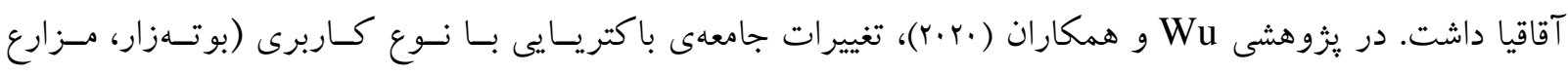
مخروطى، جنگل طبيعى و مزرعهى ذرت) را بررسى كردند. اين محققان كزارش كردند كسهـ در مقايسـه بــا جنـــل و

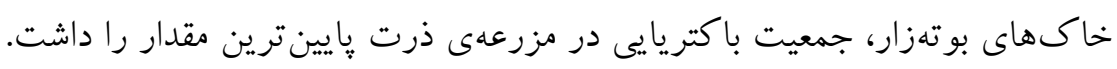


موقعيتهاى مختلف شيب مىتواند با كنترل حركت آب، مواد آلى و عناصر غذايى، در ايجاد تنوع مكانى ويثگى -

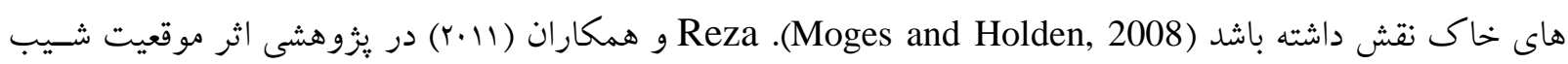
را بر شاخصهاى ميكروبى بررسى كردند. اين محققان كزارش كردند كه موقعيت شيب بر كـربن زيتـوده ميكروبسى، نيتروزن زيتوده ميكروبى، فسفر زيتوده ميكروبى، اسيد فسفاتاز و فعاليت دهيدروزناز اثر معنسى دارى داشــت. بيشـترين

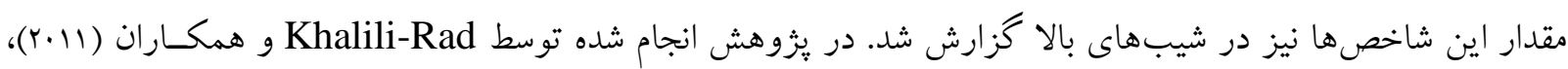

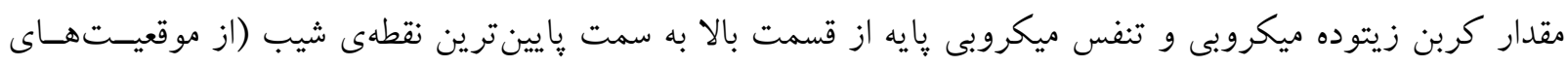

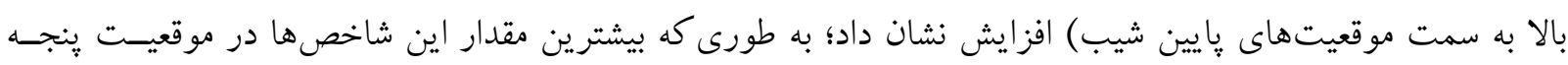

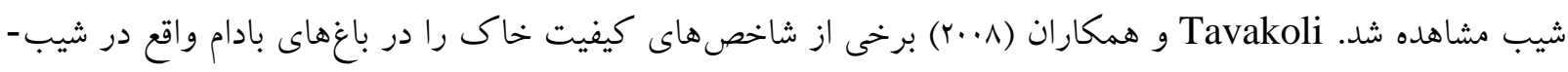

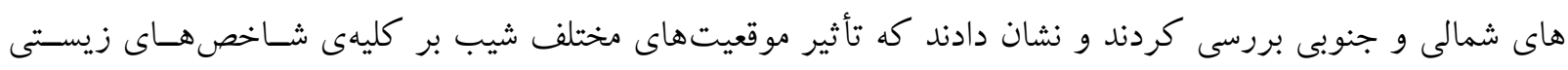

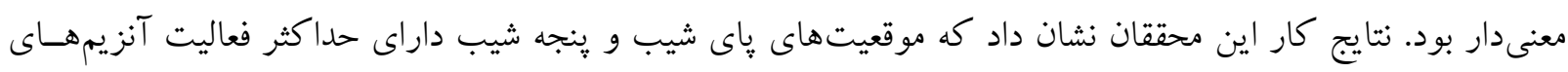

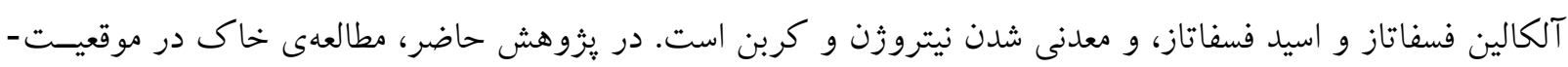

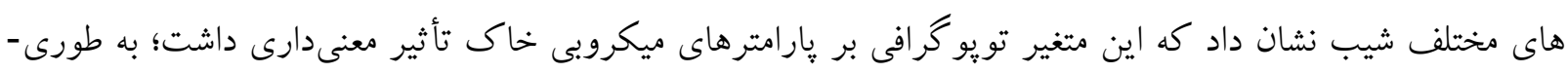

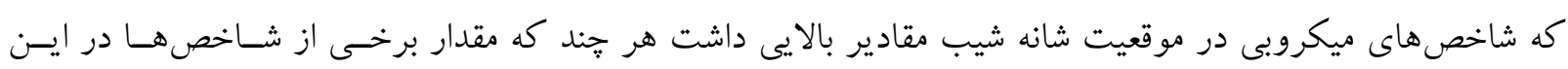

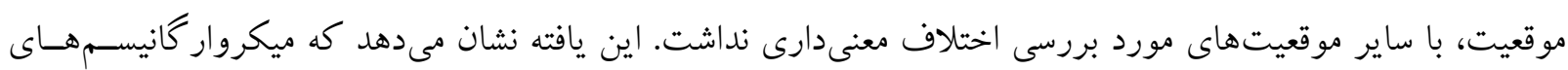

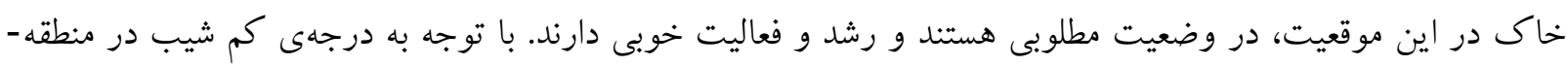

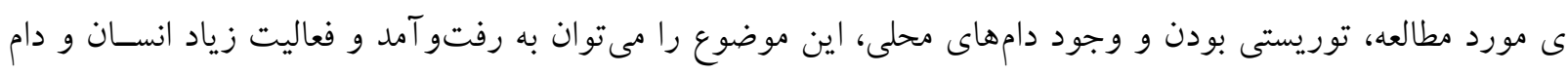

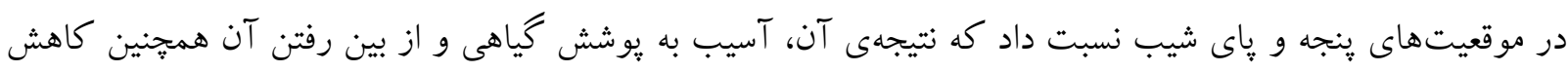

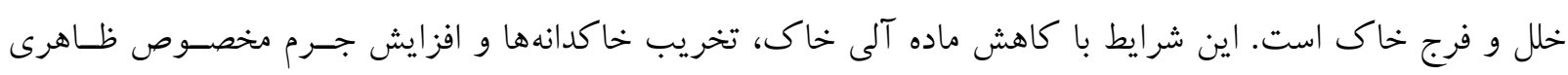

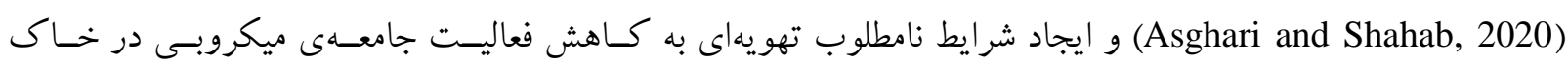
موقعيتهاى پايين شيب منجر شدهاست.

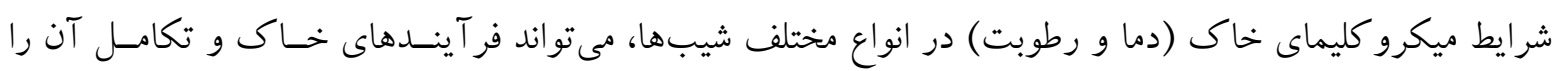

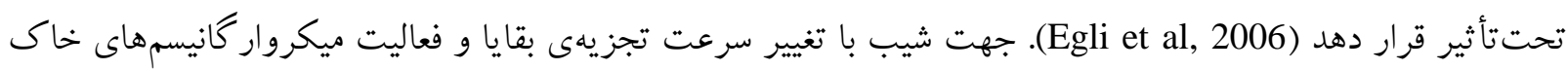

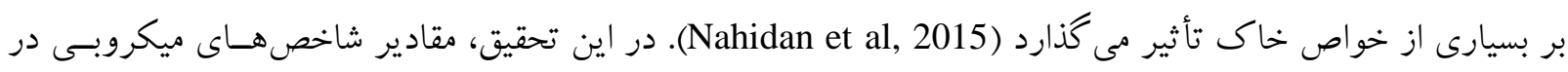

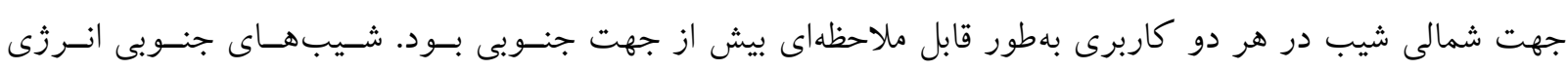

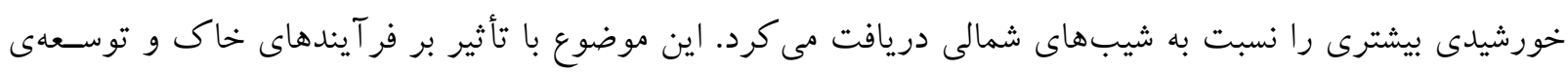

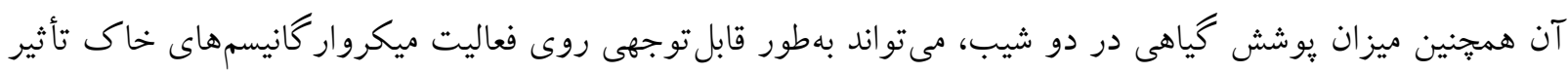

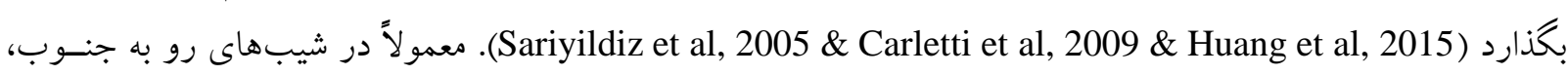
تعداد و فعاليت جامعهى ميكروبى خاكى به دليل دماى بالا، آب كم، تخلخل هايين و عواقب نامطلوب ناشسى از يوشـش به

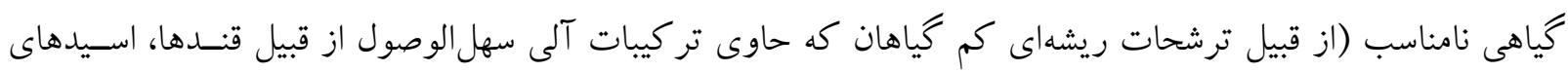

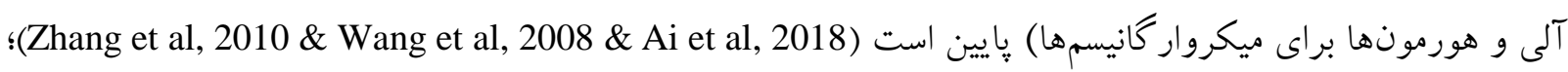
يافتهاى اين يزوهش نيز حاكى از تعداد و فعاليت كم ميكروار كانيسمها در خاكىهاى واقع در شيب جنين جنوبى بود. Ai و 


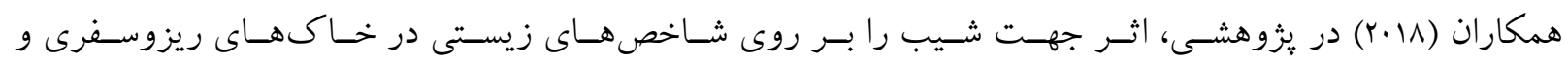

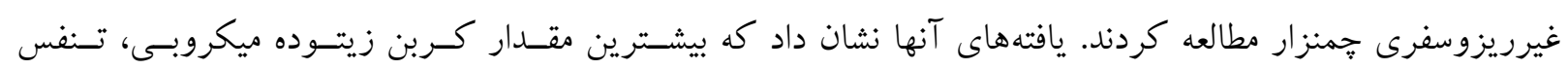
ميكروبى پايه، تنفس ناشى از بستره و PLFA" كل، در خاك غيرريزوسفرى جمنزار در جهت شمالى شـيب مشــاهده شد. مقدار اين شاخصهاى زيستى در خاك ريزوسفرى جهت هاى متفاوت (شمالى، جنوبى و شـمال غربسى)، اخستلاف

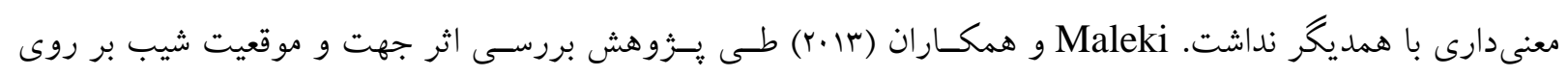
برخى از ويز گیهاى خاك كزارش دادند كه جهت شيب بر مقدار تنفس ميكروبى خاكى تأثير داشت و بيشترين مقدار اين پارامتر، در شيب جهت شمال شرقى و زمين آيش همجنين شيب جهت شرقى و زمين تحت كشت ينبه اندازه گيرى

سهم ميكروبى يا نسبت ميكروبى، شاخص زيستى مهمى است كه از آن براى بررسى كيفيت خاك استفاده مىشود.

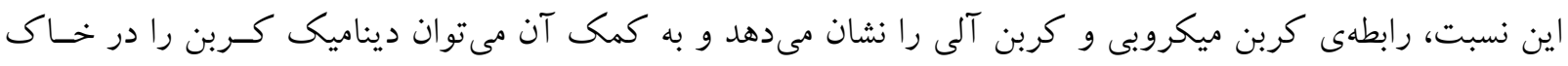

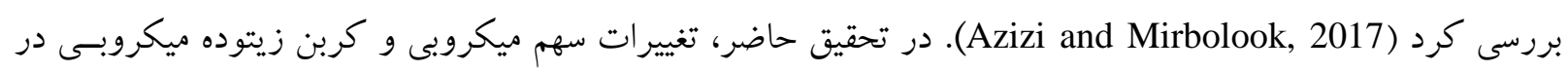

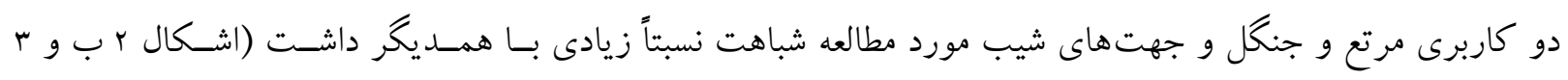
الف) كه علت اين موضوع مىتواند تغييرات نسبتاً كم كربن آلى خاك باشد (Asghari and Shahab, 2020). بنابراين،

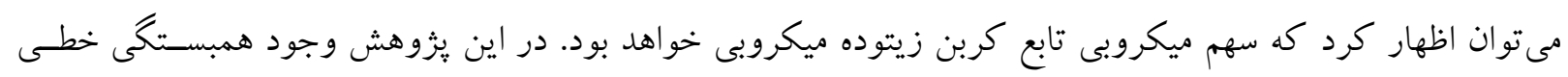

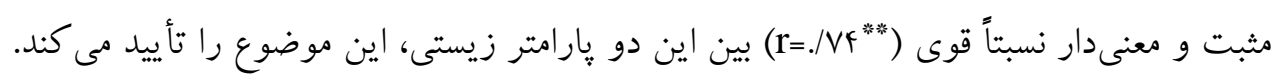

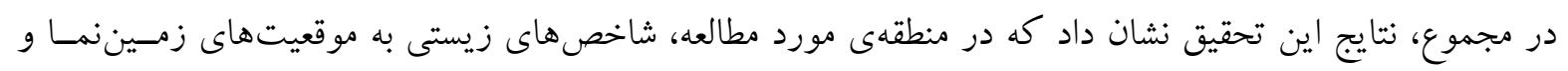

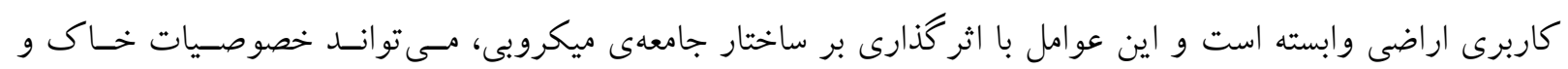

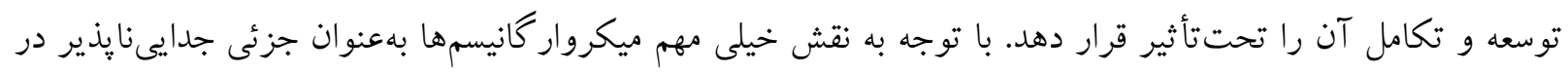
اكوسيستم خاك و تأثير اين جزء بر خواص فيزيكى، شيميايى و تغذيهاى اين اكوسيستم، مىتوان با فراهم كردن شرايط

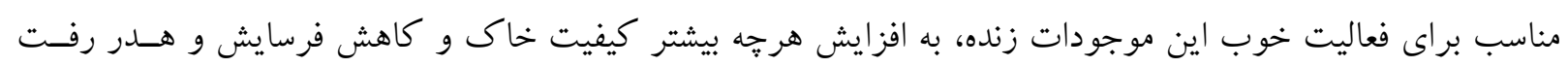
آن كمى بسيارى كرد.

1. Ai, Z. M.; He, L. R.; Xin, Q.; Yang, T.; Liu, G. B.; S. Xue, 2017a. Slope aspect affects the non-structural carbohydrates and $\mathrm{C}: \mathrm{N}: \mathrm{P}$ stoichiometry of Artemisia sacrorum on the Loess Plateau in China, Catena, 152, 9-17.

2. Ai, Z. M.; Zhang, J. Y.; Liu, H. F.; Xue, S.; \& G. B. Liu, 2018. Influence of slope aspect on the microbial properties of rhizospheric and non-rhizospheric soils on the Loess Plateau, China, Solid Earth, 9, 1157-1168.

3. Alef, K., \& P. Nannipieri., (1995). Methods in Applied Soil Microbiology and Biochemistry. Academic Press. London. 453p.

4. Alemayehu, K., 2007. Effects of different land use systems and topography on selected soil properties at Delbo Watershed, Wolayita Zone, southern Ethopia. M.Sc. Thesis. Hawassa University, Hawassa, Ethopia.

\footnotetext{
* Phospholipid-derived fatty acid
} 
5. Amirinejad, A. A., \& S. Ghotbi., (2018). The Impact of Land Use Change on Soil Physical Quality in Gilan-e-Gharb Region. Journal of Water and Soil Science (Science and Technology of Agriculture and Natural Resources. 22, 41-51.

6. Andersen, R.; Wells, C.; Macrae, M.; \& J. Price, 2013. Nutrient mineralisation and microbial functional diversity in a restored bog approach natural conditions 10 years post restoration, Soil Biology and Biochemistry, 64, 37-47.

7. Anderson, J. P. E., 1982. Soil respiration. In: Page A.L. and Mille R.H. (Ed.), Methods of Soil Analysis, Part 2, Chemical and Micro Biological Properties, American Society of Agronomy, Madison, W.I, pp. 831-871.

8. Ascher, J.; Sartori, G.; Graefe, U.; Thornton, B.; Ceccherini, M.; Pietramellara, G.; \& M. Egli, 2012. Are humus forms, mesofauna and microflora in subalpine forest soils sensitive to thermal conditions?, Biology and Fertility of Soils, 48, 709-725.

9. Asghari, S. h., \& H. Shahab Arkhazloo., (2020). Effects of Land Use and Slope on Soil Physical, Mechanical and Hydraulic Quality in Heyran Neck, Ardabil Province. journal of Environmental Erosion Research. 37, 79-91.

10. Asghari, S. h.; Ahmadnejad, S.; \& F. Keivan Behjou, 2016. Deforestation effects on soil quality and water retention curve parameters in eastern Ardabil, Iran, Eurasian Soil Science, 49(3), 338-346.

11. Azizi, E., \& A. Mirbolook., (2017). he Effect of Cr(VI) and Vermicompost on Some of Microbial and Ecophysiological Indices of Soil. Water and Soil Science. 27(4), 13-25.

12. Bardelli, T; Gómez-Brandón, M; Ascher-Jenull, J; Fornasier, F; Arfaioli, P; Francioli, D; Egli, M; Sartori, G; Insam, H; \& G. Pietramellara, 2017. Effects of slope exposure on soil physicochemical and microbiological properties along an altitudinal climosequence in the Italian Alps, Science of the Total Environment, 575, 1041-1055.

13. Bunemann, E. K; Bongiorno, G; Bai, Z. G; Creamer, R; Deyn, G. B; de Goede, R. G. M; de Fleskens, L; Geissen, V; Kuijper, T. W. M; Mäder, P; Pulleman, M. M; Sukkel, W; Groenigen, J. W.; \& L. Brussaard, 2018. Soil quality - A critical review, Soil Biology and Biochemistry, $120,105-125$.

14. Card, S. M., \& S. A. Quideau., 2010. Microbial community structure in restored riparian soils of the Canadian prairie pothole region. Soil Biology and Biochemistry. 42, 1463-1471.

15. Carletti, P; Vendramin, E; Pizzeghello, D; Concheri, G; Zanella, A; Nardi, S; \& A. Squartini, 2009. Soil humic compounds and microbial communities in six spruce forests as function of parent material, slope aspect and stand age, Plant Soil, 315, 47-65.

16. Carter, M. R.; Gregorich, E. G.; Angers, D. A.; Donald, R. G.; \& M. A. Bolinder, 1998. Organic C and N Storage and Organic C Fractions in Adjacent Cultivated and Forested Soils of Eastern Canada, Soil \& Tillage Research, 47, 253-261.

17. Cuneyt unver, M.; Kucuk, M.; Tufekcioglu, A.; \& Y. Dogan, 2010. effect of different land use on soil respiration in winter, Egyptian Journal of Experimental Biology (Botany), 6(1), 1519.

18. Dearborn, K. D., \& R. K. Danby., (2017). Aspect and slope influence plant community composition more than elevation across forest- tundra ecotones in subarctic Canada. Journal of Vegetation Science. 28, 595-604.

19. Dornbush, M. E., 2007. Grasses, litter and their interaction affect microbial biomass and soil enzyme activity, Soil Biology and Biochemistry, 39, 2241-2249.

20. Egli, M.; Mirabella, A.; Sartori, G.; Zanelli, R.; \& S. Bischof, 2006. Effect of north and south exposure on weathering rates and clay mineral formation in Alpine soils, Catena, 67,155174.

21. Fan, L. C.; Yang, M. Z.; \& W. Y. Han, 2015. Soil Respiration under Different Land Uses in Eastern China. PLOS ONE. DOI:10.1371/journal.pone.0124. 
22. Geisseler, D., \& W. R. Horwath., (2009). Short-term dynamics of soil carbon microbial biomass and soil enzyme activities compared to long-term effects of tillage in irrigated rowcrops. Biology and Fertility of Soils. 46, 65-72.

23. Gilliam, F. S.; Hédl, R.; Chudomelová, M.; McCulley, R. L.; \& J. A. Nelson, 2014. Variation in vegetation and microbial linkages with slope aspect in amontane temperate hard wood forest, Ecosphere, 5, 1-17.

24. Haghighi, F.; Gorji, M.; \& F. Shorafa, 2010. A study of the effects of land use changes on soil physical properties and organic matter, land degradation \& development, 21, 496-502.

25. Hooper, D. U., \& P. M. Vitousek., (1998). Effect of plant composition and diversity on nutrient cycling. Ecological Monographs. 68,121-149.

26. Huang, Y. M.; Liu, D.; \& S. S. An, 2015. Effecf of slope aspect on soil nitrogen and microbial properties in the Chinese Loess region, Catena, 135-145.

27. Jenkinson, D. S., \& J. N. Ladd., (1981). Microbial biomass in soil, measurement and turnover. Soil Biology and Biochemistry. 5, 415-471.

28. Khalili-Rad, M.; Nourbakhsh, F.; Jalalian, A.; \& M. Karimian Eghbal, 2011. The Effects of Slope Position on Soil Biological Properties in an Eroded Toposequence, Arid Land Research and Management, 25, 308-312.

29. Khormali, F.; Ajami, M.; Ayoubi, S.; Srinivasarao, Ch.; \& S. P. Wani, 2009. Role of deforestation and hillslope position on soil quality attributes of loess-derived soils in Golestan province. Iran, Agricultural, Ecosystems and Environment, 134, 178-189.

30. Lemenih, M.; Karltun, E.; \& M. Olsson, 2005. Assessing soil chemical and physical property responses to deforestation and subsequent cultivation in smallholders farming system in Ethiopia, Agriculture, Ecosystems \& Environment, 105, 373-386.

31. Liu, M.; Zheng, R.; Bai, S.; \& J. Wang, 2017. Slope aspect influences arbuscular mycorrhizal fungus communities in arid ecosystems of the Daqingshan Mountains, Inner Mongolia, North China, Mycorrhiza, 27, 189-200.

32. Maleki, S.; Khormali, F.; Kiani, F.; \& A. R. Karimi, 2013. Effect of slope position and aspect on some physical and chemical soil characteristics in a loess hillslope of Toshan area, Golestan Province, Iran, Journal of Water and Soil Conservation, 20, 94-112 (In Persian).

33. Martens, R., 1991. Methodenzur quanttitativen Bestimmung undcharakterisierungder mikrobiellen Biomasse in Boden. Eigenverlag des Institutes fur Bodenbiobgie der FAL Braunschweig.

34. Moges, A., \& N. M. Holden., (2008). Soil fertility in relation to slope position and agricultural land use: a case study of Umbulo catchment in southern Ethopia. Journal of Environmental Management. 42, 753-763.

35. Nabiollahi, K.; Golmohamadi, F.; Taghizadeh-Mehrjardi, R.; Kerry, R.; \& M. Davari, 2018. Assessing the effects of slope gradient and land use change on soil quality degradation through digital mapping of soil quality indices and soil loss rate, Geoderma, 318, 16-28.

36. Nahidan, S.; Nourbakhsh, F.; \& M. R. Mosaddeghi, 2015. Variation of soil microbial biomass $\mathrm{C}$ and hydrolytic enzyme activities in a rangeland ecosystem: are slope aspect and position effective?, Archives of Agronomy and Soil Science, 61, 797-811.

37. Ollinger, S. V.; Smith, M. L.; Martin, M. E.; Hallett, R. A.; Goodale, C. L.; \& J. D. Aber, 2002. Regional variation in foliar chemistry and $\mathrm{N}$ cycling among forests of divers history and compositions, Ecology, 83, 339-355.

38. Padiab, J.; Abbasi-Kalo, A.; \& F. Keivan-Behju, 2020. Behavior of soil physical and chemical properties against forest land use change (case study: Khalkhal County, Ardabil Province), Quarterly Journal of Environmental Erosion Research, 36 (9:4), 17-34 (In Persian).

39. Qin, Y. Y.; Feng, Q.; Holden, N. M.; \& J. J. Cao, 2016. Variation in soil organic carbon by slope aspect in the middle of the Qilian Mountains in the upper Heihe River Basin, China, Catena, 147, 308-314. 
40. Reza, S. K.; Baruah, U.; Sarkar, D.; \& D. P. Du, 2011. Influence of slope positions on soil fertility index, soil evaluation factor and microbial indice in acid soil of Humid Subtropical India, Indian Journal of Soil Conservation, 39, 44-49.

41. Royer-Tardif, S., Bradley, R.L., Pearce, D.A., Kowalchuk, G.A. 2010. Patterns of bacterial diversity across a rang of Antarctic terrestrial habitats. Environmental Microbiology. 42: 813821.

42. Sariyildiz, T., Anderson, J., Kucuk, M. 2005. Effects of tree species and topography on soil chemistry, litter quality, and decomposition in Northeast Turkey. Soil Biology and Biochemistry. 37: 1695-1706.

43. Shukla, M.K., La, R.; \& M. Ebinger, 2006. Determining Soil Quality Indicators by Factor Analysis, Soil \& Tillage Research, 87, 194-204.

44. Sidari, M.; Ronzello, G.; Vecchio, G.; \& A. Muscolo, 2008. Influence of slope aspects on soil chemical and biochemical properties in a Pinus laricio forest ecosystem of Aspromonte (Southern Italy), European Journal of Soil Biology, 44, 364-372.

45. Smith, J.; Halvorson, J. J.; \& H. Jr. Bolton, 2002. Soil properties and microbial activity across a $500 \mathrm{~m}$ elevation gradient in a semi-arid environment, Soil Biology and Biochemistry, 43, 1749-1757.

46. Sui, X.; Zhang, R.; frey, B.; Yang, L.; Li, M. H.; \& N. Hongwei, 2019. Land use change effects on diversity of soil bacterial, Acidobacterial and fungal communities in wetlands of the Sanjiang Plain, northeastern China. SCIENTIFIC REPORTS. 9:18535, 113.|https://doi.org/10.1038/s41598-019-55063-4.

47. Tatanah Nanganoa, L.; Nambangia Okolle, J.; Missi, V.; Roberto Tueche, J.; Dopgima Levai, L.; \& J. Nkengafac Njukeng, 2019. Impact of Different Land-Use Systems on Soil Physicochemical Properties and Macrofauna Abundance in the Humid Tropics of Cameroon. Hindawi, Applied and Environmental Soil Science. /doi.org/10.1155/2019/5701278.

48. Tavakoli, M.; Raiesi, F.; \& M. H. Salehi, 2008. Evaluation of selected soil quality indicators in almond orchard located on north and south-facing slopes in Saman region, Shahrek, Journal of Agriculture and Natural Resources, 15(1), 1-13.

49. Tshering Lepcha, N., \& N. B. Devi., (2020). Effect of land use, season and soil depth on soil microbial biomass carbon of Eastern Himalayas, Ecological processes, 9, 65, 1- 14.

50. Tsui, C. C.; Chen, Z. S.; \& C. F. Hsieh, 2004. Relationships between soil properties and slope position in a lowland rain forest of southern Taiwan, Geoderma, 123, 131-142.

51. Van Leeuwen, J. P.; Djukic, I.; Bloem, J.; Lehtinen, T.; \& L. Hemerik, 2017. Effects of land use on soil microbial biomass, activity and community structure at different soil depths in Danube floodplain, European Journal of Soil Biology, 79, 14-20.

52. Wang, L.; Wang, Q.; Wei, S.; Shao, M. A.; \& Y. Li, 2008. Soil desiccation for Loess soils on natural and regrown areas, Forest Ecology and Management, 255, 2467-2477.

53. Wu, S. J.; Deng, J. J.; Yin, Y.; Qin, S. J.; Zhu, W. X.; Zhou, Y. B.; Wang, B.; Ruan H.; \& L. Jin, 2020. Bacterial Community Changes Associated with Land Use Type in the Forest Montane Region of Northeast China. Forests. 11, 40; doi:10.3390/f11010040.

54. Yimer, F.; Messing, I.; Ledin, S.; \& A. Abdelkadir, 2008. Effect of different land use types on infiltration capacity in a catchment in the high lands of Ethopia, Soil Use and Management, 24, 344-349.

55. Zhang, G. H.; Liu, G. B.; \& G. L. Wang, 2010. Effect of Caragana korshinskii Kom. Cover on run off, sediment yield and nitrogen loss, International Journal of Sediment Research, 25(3), 245- 257. 


\title{
Assessment the effect of Slope aspect and position on some soil microbial indices in rangeland and forest
}

\author{
Ali-Ashraf Soltani Toularoud : Associate professor, Department of Soil Science and engineering, Faculty of \\ Agriculture and Natural Resources, University of Mohaghegh Ardabili, Ardabil \\ Shokrollah Asghari: Associate professor, Department of Soil Science and engineering, Faculty of Agriculture \\ and Natural Resources, University of Mohaghegh Ardabili, Ardabil
}

Article History (Received: 2021/05/1

Accepted: 2021/05/29)

\section{Extended abstract}

\section{1- Introduction}

Topography is one of the effective factors in soil formation and development. Topographical features such as slope aspect and position, by affecting soil temperature, evaporation capacity, soil moisture content, soil organic matter, precipitation, movement, and accumulation of soil solution can impress soil microbial properties. For investigating the effect of land-use change on soil ecosystem functioning because of human activities, it is essential to study the soil processes in disparate land-use systems and to preserve and regenerate the capability of soil to deliver ecosystem services. This study aimed at evaluating the effect of slope aspect and position on soil microbial indices in rangeland and forest areas of Heyran neck.

\section{2- Methodology}

This experiment was accomplished as factorial on the basis of a randomized complete block design with three treatments containing land use (forest and rangeland), slope aspects (north and south), and three slope positions (shoulder, footslope, toeslope), and four repetitions in Heyran neck, one of the functions of Astara city in Guilan province. Totally, 48 disturbed soil samples were taken from forest and rangeland at two aspects and three slope positions. From soil biological indices, soil microbial population, soil basal, and substrate-induced respiration (BR and SIR), microbial biomass carbon (MBC), and microbial quotient $\left(\mathrm{q}_{\mathrm{mic}}\right)$ were measured. Soil microbial population was determined by the most probable number method (MPN method). The basal soil respiration was determined by placing $50 \mathrm{~g}$ of soil in glass jars together with $10 \mathrm{~mL} 0.05 \mathrm{~N} \mathrm{NaOH}$ in $20 \mathrm{~mL}$ glass vials. All samples were incubated for $24 \mathrm{~h}$ at $25 \pm 1{ }^{\circ} \mathrm{C}$, and the $\mathrm{CO}_{2}$ that evolved and was trapped during the period was determined by titration of the $\mathrm{NaOH}$ with $0.1 \mathrm{~N} \mathrm{HCl}$. Substrate-induced respiration was determined by measuring the $\mathrm{CO}_{2}$ production from $50 \mathrm{gr}$ fresh soil. The soil samples included $1 \%$ glucose, were first placed in a glass jar. Then, an absorption bottle that was filled with $25 \mathrm{ml}$ of $0.1 \mathrm{~N} \mathrm{NaOH}$ was carefully put in the glass jar, and the glass jar was precisely sealed. The jar was then incubated at $25 \pm 1{ }^{\circ} \mathrm{C}$ for $6 \mathrm{~h}$. The evolved $\mathrm{CO}_{2}$ was trapped by $\mathrm{NaOH}$ and determined by titration of $\mathrm{NaOH}$ with $0.1 \mathrm{~N}$ HCL. Microbial biomass carbon was estimated by the chloroform fumigation and extraction method. Microbial quotient was calculated by dividing microbial biomass carbon (MBC) with soil organic carbon (SOC). Data's normality was assessed through Kolmogorov-Smirnov test. The analysis of variance and comparison of means by Duncan test and Pearson correlations were done using SPSS software. Figures were prepared using Excel software.

\footnotetext{
${ }^{1}$ Corresponding Author: ali_soltani_t@@yahoo.com
} 


\section{3-Results \& Discussion}

The results showed that the content of all biological parameters measured in the forest soils was significantly higher than in the rangeland soils. In both land uses and in all slope positions, the highest values of basal soil and substrate-induced respiration, microbial population, and microbial biomass carbon were measured in the north-facing slope. In the studied land uses and slope aspects, all biological indicators except the microbial quotient had the highest value in the shoulder position. In the south-facing slope, the content of microbial quotient in the toeslope position was measured more than in other positions. Still, there was no significant difference from the value of this index in the shoulder position. The highest value of microbial quotient $\left(1.95 \mathrm{mgC}_{\text {mic }} \cdot \mathrm{g}^{-1} \mathrm{C}_{\text {org }}\right)$ was observed in the north-facing slope on the shoulder, which was not significantly different from the value of this index in the footslope and toeslope positions of north-facing slope and also the shoulder and toeslope of south-facing slope. In forest land use, the content of microbial quotient in both north-facing $\left(1.91 \mathrm{mgC}_{\mathrm{mic}} \cdot \mathrm{g}^{-}\right.$ $\left.{ }^{1} \mathrm{C}_{\text {org }}\right)$ and south-facing $\left(1.9 \mathrm{mgC}_{\text {mic }} \cdot \mathrm{g}^{-1} \mathrm{C}_{\text {org }}\right)$ slopes was almost equal, which was significantly different from its value in both slope aspect of rangeland. The correlation between all biological indices at the level of one percent probability was positive and significant. There was the highest correlation between basal soil and substrate-induced respiration $(\mathrm{r}=0.94 * *)$ as well as microbial biomass carbon and substrate-induced respiration $\left(\mathrm{r}=0.89^{* *}\right)$.

\section{4- Conclusions}

Overall, the results of this study showed that biological indices are dependent largely on landscape and land use, and by affecting the structure of the microbial community, these factors can affect the properties of the soil and its development. Due to the significant role of microorganisms as an integral component in the soil ecosystem and the effect of this component on the physical, chemical and nutritional properties of this ecosystem, by providing suitable conditions for the good activity of these organisms, soil quality can be increased, and thus erosion will be reduced.

Key Words: biological parameters, microbial respiration, microbial population, microbial biomas carbon, soil quality, Heyran neck. 